\title{
RECORDING OF RIGHT HEART PRESSURES IN NORMAL SUBJECTS AND IN PATIENTS WITH CHRONIC PULMONARY DISEASE AND VARIOUS TYPES OF CARDIO-CIRCULATORY DISEASE ${ }^{1}$
}

\author{
By RICHARD A. BLOOMFIELD, HENRY D. LAUSON, ANDRE COURNAND, \\ ERNEST S. BREED, AND DICKINSON W. RICHARDS, JR. \\ (From the Department of Physiology of New York University College of Medicine, and the \\ Department of Medicine of Columbia University, College of Physicians and \\ Surgeons, and the Chest Service (Columbia University \\ Division), Bellevue Hospital, New York City)
}

(Received for publication March 4, 1946)

\section{INTRODUCTION}

The development of the technique of recording pressures in the right auricle and ventricle by connecting an intra-cardiac catheter ${ }^{2}$ to a Hamilton manometer has made possible for the first time in human subjects the direct quantitative study of some aspects of the right heart function and of the pulmonary circulation, in health and in disease. The method has been previously described in brief (1)..$^{3}$.In the present report tracings obtained from normal subjects and from patients suffering from a variety of pulmonary and circulatory diseases are described in greater detail. The intracardiac pressure curves are analyzed in relation to the different phases of the cardiac cycle, and an attempt is made to give an interpretation of the abnormal curves in terms of the pathological conditions with which they are associated. While reference will occasionally be made to other data routinely obtained in this study, including cardiac output, blood volume, x-rays and electrocardiograms, complete presentation of these is beyond the scope of this paper.

1 This work was carried on under a contract, recommended by the Committee on Medical Research, between the Office of Scientific Research and Development, and Columbia University, with the collaboration of New York University. Additional support was provided by the Commonwealth Fund.

2 Obtained from the U. S. Catheter and Instrument Corporation, Glens Falls, New York.

3 An independent study of the right heart pressures in man was presented by J. Lenègre and $P$. Maurice before the Société de Cardiologie on May 21, 1944, and reported in the Archives des Maladies du Coeur et des Vaisseaux, No. 9-10, Sept.-Oct. 1944. Mean pressures were measured with a saline manometer: By personal communication, it has been learned that auricular and ventricular pressures have been recorded more recently by a modified piezographic method.

\section{METHODS}

A specially designed ureteral type of catheter was inserted into an antecubital vein, and the catheter tip directed into the right auricle or ventricle under fluoroscopic visualization according to the technique described earlier (2 to 4). In the majority of instances a catheter of single lumen was used. A double-lumen catheter, recently designed (5), was employed for simultaneous study of the pressure cycle in both auricle and ventricle in a few selected cases, which are discussed in the text. With proper precaution it has proved feasible to make determinations in a wide variety of patients with safety and apparent accuracy. Due attention to the details of the technique (i.e. avoidance of pain, rapid execution of the various procedures, careful selection of the number of determinations to be made, in the light of the patient's clinical status) has resulted in the absence of any significant complication attributable to the method of study. However, provocation of ectopic ventricular beats by the catheter in the ventricle, probably due to contact of the catheter tip with the inter-ventricular septum, has been sufficiently frequent, especially in cardiac patients, to indicate caution in the matter of catheter position. Observation of the continuous electrocardiogram by one of the operators may detect this at once. Thus far it has always been possible to manipulate the catheter in such fashion as to bring about prompt cessation of the abnormal stimuli. No induced arrhythmias have been observed when the tip of the catheter was located in the auricle.

The specifications of the cardiac manometer were essentially those given by Hamilton (6), except that the lead tubing was about 1.5 meters long. The natural frequency was usually 25 to 50 cycles per second, with the catheter attached, and the sensitivity of the instrument for the camera distance of 2 meters was 0.5 to $1.0 \mathrm{~mm}$. per $\mathrm{mm}$. $\mathrm{Hg}$.

In the majority of studies the record also included a simultaneous registration of the electrocardiogram with a string galvanometer, the respiratory cycle through a modified Marey pneumograph, and the femoral arterial pressure, for which a second Hamilton manometer of higher frequency and lower sensitivity was employed.

The determinations in all but a few cases were carried out with the patient recumbent and in the post-absorptive state after a night of bedrest. 


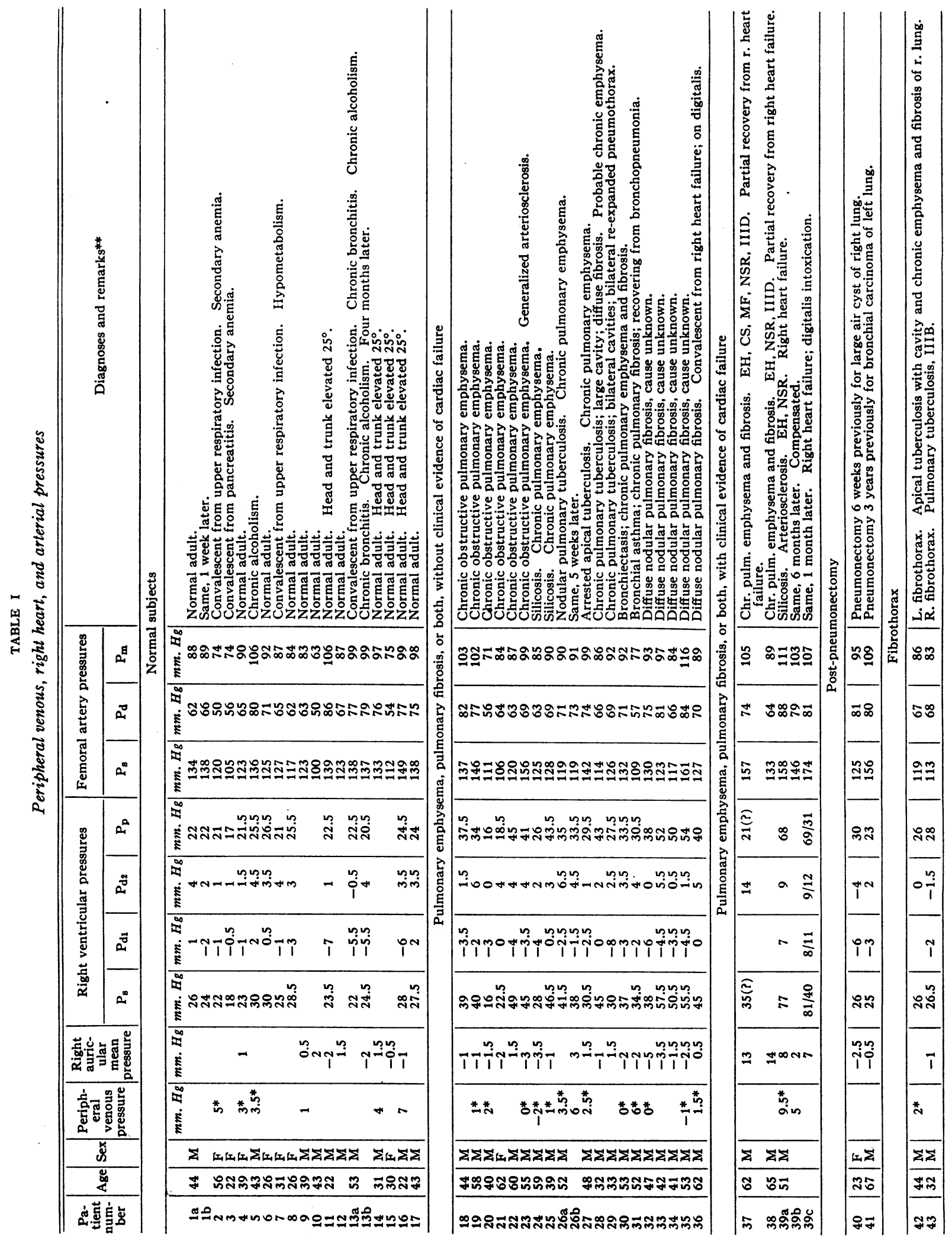




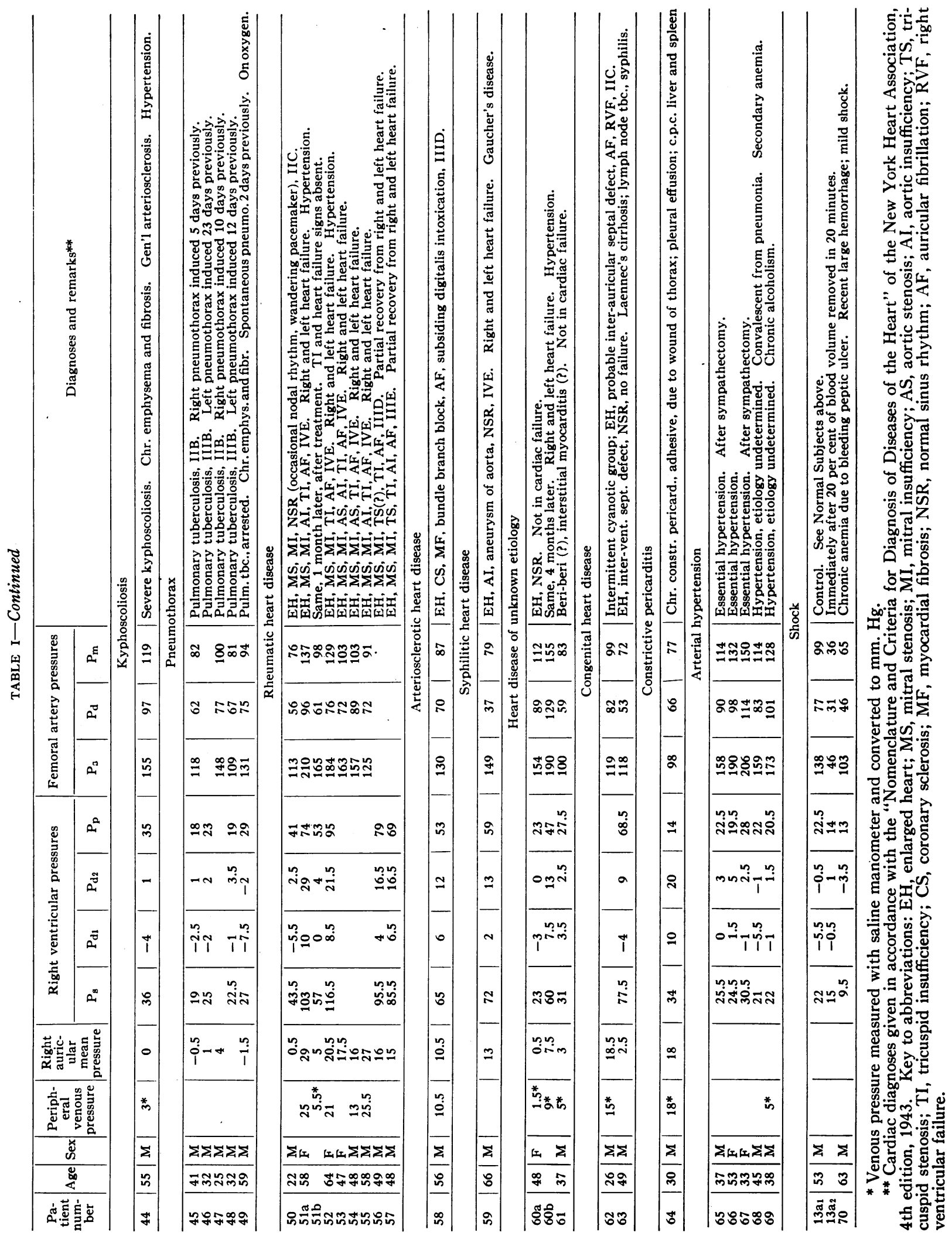


Tracings were routinely measured for pressure values in each heart beat during normal complete respiratory cycles, and the results averaged. Mean pressures were determined by planimetric integration. The data from arterial pressure records include average maximum (systolic), average minimum (diastolic), and mean pressures. For the auricle, only mean pressures are given in the tables, although momentary pressures were sometimes also measured. Because of the frequently oscillatory character of the ventricular pressure curve, the average value for the highest level attained during the ventricular ejection period was arbitrarily chosen to represent the systolic pressure, and is designated $\mathrm{P}_{\mathrm{s}}$. The pressures at two moments during ventricular diastole were measured: $(a)$ at the lowest point reached following closure of the pulmonic valve, and $(b)$ at the end of auricular systole, or when the latter was not apparent in the ventricular tracings, just before the onset of the ventricular systolic rise. These are designated $P_{d 1}$ and $P_{d 2}$, respectively (Figure 2C). The significance of the earlier diastolic pressure is discussed below. $\mathbf{P}_{\mathbf{d} 2}$ was chosen as a measure of the initial, or filling pressure, of the ventricle. The difference between the maximal systolic pressure and the pressure at the end of diastole $\left(P_{s}\right.$ minus $\left.P_{d 2}\right)$ is designated as the pulse pressure $\left(P_{p}\right)$. Auricular mean pressure proved to be an accurate index of mean ventricular diastolic pressure, as substantiated by withdrawing the catheter from ventricle to auricle during uninterrupted or momentarily interrupted recording (Figure 1B).

All pressures are recorded in $\mathrm{mm}$. $\mathrm{Hg}$ above or below atmospheric pressure taken as zero. To eliminate hydrostatic factors it is necessary to choose some horizontal plane as a level of reference. For intra-cardiac pressures it appears that this plane should pass somewhere through the heart itself and at the same time bear a reasonably constant relationship to an external landmark such as the angle of Louis. As an approximation, therefore, the depth of the center of the heart below the angle of Louis was measured from a lateral $x$-ray as the vertical distance from the angle of Louis, to the mid-point between the anterior tip of the ventricle and lowermost portion of the auricle, the patient being in the horizontal position. In normal subjects this measurement averaged $5.82 \mathrm{~cm}$., with a total range of $\pm 0.90 \mathrm{~cm}$. In patients with cardiac enlargement it averaged $5.55 \pm 1.50 \mathrm{~cm}$. In cases of emphysema it averaged $6.86 \pm 0.80 \mathrm{~cm}$. For the sake of simplicity, however, it has been decided to take the conventional venous pressure reference level of $5 \mathrm{~cm}$. below the angle of Louis as the one from which to reckon both auricular and ventricular pressures when the patient is recumbent. This level, then, could differ from zero plane exactly through the center of the heart by as much as 2 or $3 \mathrm{~mm}$. $\mathrm{Hg}$. The true reference point, moreover, will vary in any given patient with the phases of the respiratory and cardiac cycles. Hence no value of pressure except ventricular pulse pressure can be considered to have a final precision greater than \pm 2 or $3 \mathrm{~mm}$. $\mathrm{Hg}$ when patient to patient comparison is made. For studying changes in a given patient, however, the choice of a reference level is of little importance.
While the data from the present study have yielded useful information, it is realized that there may have been errors, both of technique and interpretation. In general, the sources of error are twofold: $(a)$ reference to an incorrect zero may distort pressure values and lead to a false appraisal of physiologic states; $(b)$ failure to recognize artefact may result in erroneous computation of pressure values or incorrect interpretation of physiologic events. With respect to the latter, every effort has been made to profit by the experience of others, and to detect new artefacts introduced by the present technique. Such obvious sources of invalid curves as motion by the patient, and extraneous impacts upon equipment are usually recognizable and avoidable. There remain, however, certain oscillatory phenomena which are subject to controversy, in particular those seen at the crest of systole and early in diastole, which may be due entirely to motion of the catheter or may be caused, in part at least, by oscillations of the blood mass.

\section{RESULTS}

The data in Table I are from 77 catheterizations in 70 subjects. In 12 instances, right auricular pressure tracings alone were taken; in 19, right ventricular tracings alone were taken; in 46, tracings were made from both chambers. Five patients were studied twice; one patient was studied 3 times.

It is obvious that any numerical description can give only a partial concept of the tracings, and it is therefore esential to consider not only the amplitude of pressure curves, but also their contours. The possibility of artefact must be considered whenever an unusual finding is to be evaluated. Correlation must be made with the known sequence of physiological events in the cardiac cycle, and final interpretation must be based on consideration of all the known clinical facts.

Throughout this report only the right heart pressures are discussed. The terms, auricle, auricular, ventricle and ventricular will therefore always refer to the right side of the heart.

\section{Normal subjects}

A. Right auricle. In resting recumbent normal subjects the mean auricular pressure has varied from -2 to $+2 \mathrm{~mm}$. $\mathrm{Hg}$, with respect to atmospheric pressure. The several components of the cardiac cycle are, in good curves, readily recognizable, and correspond closely to those described by Wiggers (7). The magnitude of pressure variation within the cycle is small, being of the order 


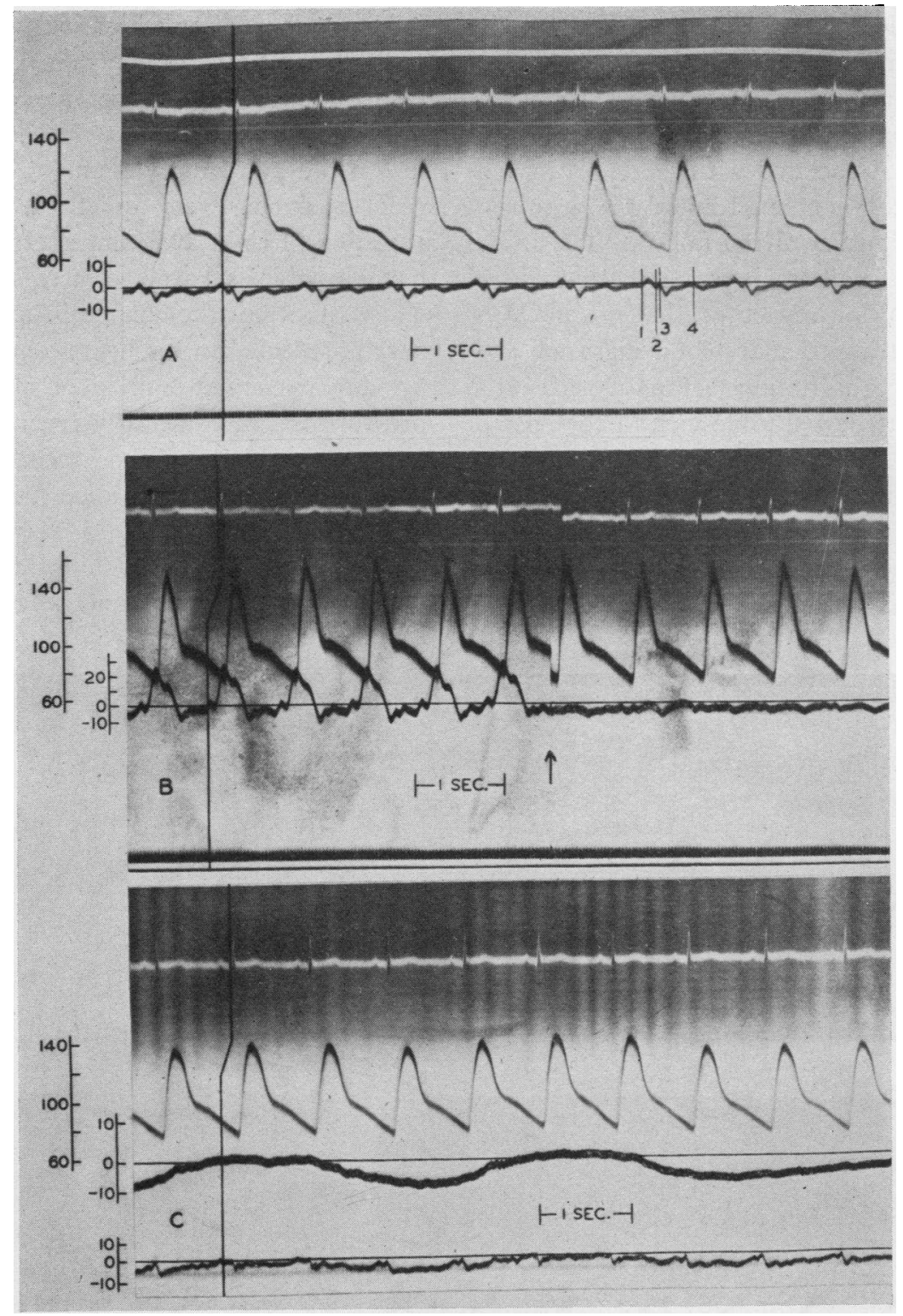

Fig. 1. A. Record from Normal Male, Patient No. 9

In this and subsequent tracings, electrocardiogram and pneumogram, where shown, are at top of film. Descent of white line indicates inspiration; ascent, expiration. Upper black curve is femoral arterial pressure; next lower is that of right auricle (as in this case) or ventricle. Time in subdivisions of 0.04 and 0.20 seconds is registered on baseline. Scales in $\mathrm{mm}$. $\mathrm{Hg}$, drawn at left of figure, represent static calibration against mercury for each case. Parallax between electrocardiogram and pressure curves is indicated by vertical line drawn through beginning of ventricular complex of electrocardiogram. It is usually equivalent to 0.13 second. Events of auricular cycle are 1 , rise of pressure due to auricular systole; 2 , sharp rise of pressure due to closure of tricuspid valve; 3 , fall of pressure due to descent of base associated with ventricular ejection; and 4, fall of pressure associated with opening of tricuspid valve and onset of ventricular filling.

B. Record from Patient No. 16, Showing Normal Ventricular and Auricular Pressures

Arrow indicates brief closure of camera while catheter tip was withdrawn from ventricle to auricle. Note correspondence between auricular and ventricular diastolic levels.

C. Femoral Arterial, Intrapleural and Auricular Pressures from Patient No. 45

Auricular pressure varies in same direction as intrapleural, but to lesser extent. Respiratory effect on arterial pressure is also apparent. At maximum expiration, intrapleural pressure appears slightly higher than auricular pressure; presumably due to error in choosing $5 \mathrm{~cm}$. below angle of Louis as reference level for auricular pressure in this patient. 
of 4 to $8 \mathrm{~mm}$. $\mathrm{Hg}$. Figure $1 \mathrm{~A}$ is an unusually satisfactory example of a normal auricular pressure record. Auricular systole appears as a monophasic positive wave, the onset of which is labelled 1 in the figure. Associated with the onset of ventricular contraction is a small initial pressure rise. 2 , followed by a rather sharp fall, 3 . The initial rise, not present in all tracings, has been ascribed by Wiggers (7) to impact of the closing $\mathrm{A}-\mathrm{V}$ valves on the intra-auricular blood mass, or possibly to slight regurgitation before closure; the pressure fall is attributed to descent of the base of the heart during ventricular ejection. During the remainder of ventricular systole the intra-auricular pressure gradually rises, until the $A-V$ valves reopen. At this moment, 4 , the pressure falls fairly abruptly as auricle and ventricle become a com- mon chamber, after which it again rises gradually until the next auricular systole. Occasionally, just before this auricular emptying phase, a small vibration may be noted simultaneous with the closure of the pulmonic valves.

Even during very quiet breathing a periodic variation of right auricular pressure is usually detectable; this is barely discernible in Figure 1A. To what extent the change in intra-thoracic pressure is reflected in the heart cannot be determined for any particular individual unless intra-pleural pressure is simultaneously recorded. Such a record, obtained by a method recently described (8), from patient No. 45 , studied prior to a refill of a pneumothorax induced 5 days previously, is shown in Figure 1C. While this subject was not wholly normal, there is no reason to believe that

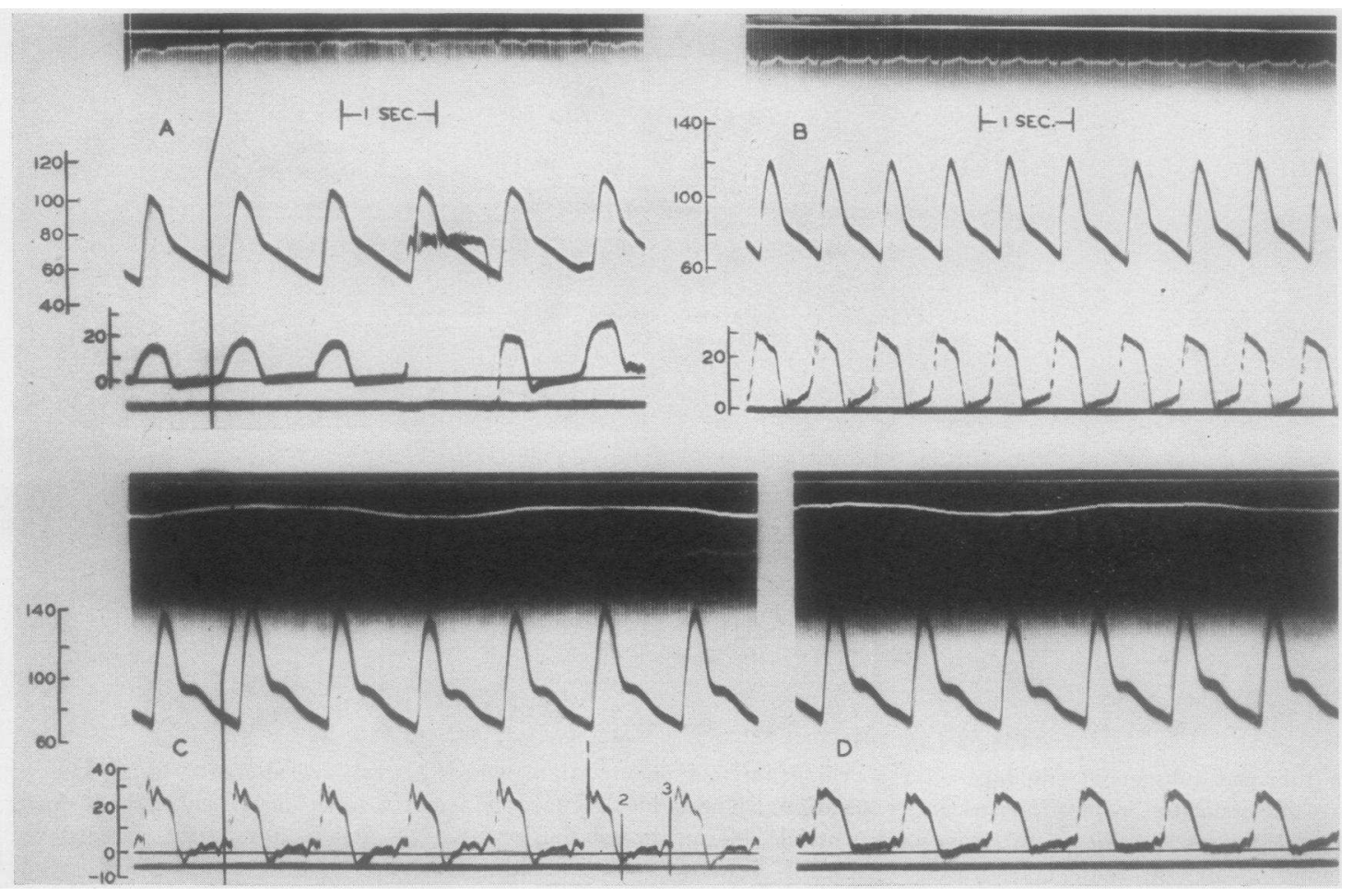

Fig. 2. Representative Records from Normal Right Ventricle

The sudden interruption in $A$ was caused by flushing citrated fluid through the manometer to insure continued patency of catheter. There is high frequency vibration of extraneous origin in $B$. In $C$, lines marked 1,2, and 3, indicate time of cardiac cycle at which $P_{s}, P_{d 1}$, and $P_{d 2}$, respectively, were measured. These 3 points were measured in each cardiac cycle comprising one or more complete respiratory cycles, and results averaged. Records $C$ and $D$ were obtained from the same patient (No. 17), the latter after catheter position in ventricle had been slightly changed. Note decrease in amplitude of oscillations while general form of pulse is unchanged. Data in Table $\mathrm{I}$ for this patient were measured from $D$. See text for details. 
his circulation was abnormal. The depth of respiration is somewhat greater than in Figure 1A, due to slight emotional disturbance. The ratio of the change of auricular pressure during the respiratory cycle to the change of intra-pleural pressure is about $5: 8 \mathrm{~mm} . \mathrm{Hg}$, or 60 per cent.

B. Right ventricle. As shown in Table I the maximum systolic pressure in normal subjects has ranged between 18 and $30 \mathrm{~mm}$. $\mathrm{Hg}$ above atmospheric pressure, averaging $25 \mathrm{~mm}$. $\mathrm{Hg}$ for this series. The diastolic pressures have ranged from between -7 and $+2 \mathrm{~mm}$. $\mathrm{Hg}$ at the lowest point early in diastole $\left(\mathrm{P}_{\mathrm{d} 1}\right)$, to between -0.5 and +4.5 $\mathrm{mm} . \mathrm{Hg}$ at the end of diastole $\left(\mathrm{P}_{\mathrm{d} 2}\right)$. It is of interest that the right ventricular pulse pressure range $\left(P_{p}\right)$ was, with one exception, within the narrow limits of 20.5 to $26.5 \mathrm{~mm}$. $\mathrm{Hg}$, and averaged $22.5 \mathrm{~mm}$. $\mathrm{Hg}$.

Respiratory rate and intra-thoracic pressure variations affect the ventricular pressure curve, as is demonstrated in Figure 2D. In the majority of ventricular tracings, auricular systole is manifest as a small wave occurring just before the onset of ventricular systole (Figures 1B, 2D). Three main types of ventricular systolic contour have been observed. Figure 2A from patient No. 3 is that of an infrequently obtained curve which is smoothly rounded during ejection, falls to a mini- mum following closure of the semi-lunar valves, and then rises in a gradual and uninterrupted manner during diastole. Equally infrequent is the curve shown in Figure 2B (patient No. 6), which reaches a maximum early in systole, has a rather flattened slope during the rest of the ejection period, and in its diastolic portion resembles the first type. The most frequently observed curves are of the type shown in Figure $1 \mathrm{~B}$ from patient No. 16, and Figures 2C and 2D from patient No. 17. The summit is marked by one or more low frequency oscillations which may occur at any time during maximal ejection; a small, brief dip below the general diastolic level is usually seen following closure of the pulmonic valve; this dip may initiate a series of damped, low frequency oscillations which last during a variable portion of diastole.

\section{Lesions predisposing to pulmonary hyper- tension and right ventricular strain}

\section{$A$. In the absence of right ventricular failure}

1. Chronic pulmonary disease. This group consists of patients with chronic pulmonary emphysema, with chronic pulmonary fibrosis, or with both. The diagnosis of emphysema was based on the measurement of the residual air, the ratio of

TABLE II

Hematocrit, lung volume data, and right ventricular pulse pressures from patients with chronic pulmonary emphysema, fibrosis, or both

\begin{tabular}{|c|c|c|c|c|c|c|c|c|}
\hline \multirow{2}{*}{$\begin{array}{l}\text { Patient } \\
\text { number }\end{array}$} & \multirow{2}{*}{ Hematocrit } & \multicolumn{2}{|c|}{ Total lung volume } & \multicolumn{2}{|c|}{ Residual air } & \multicolumn{2}{|c|}{$\frac{\text { Residual air }}{\text { Total lung vol. }} \times 100$} & \multirow{2}{*}{$\begin{array}{l}\text { Right ven- } \\
\text { tricular pulse } \\
\text { pressure }\end{array}$} \\
\hline & & Predicted & Observed & Predicted & Observed & Predicted & Observed & \\
\hline $\begin{array}{l}18 \\
19 \\
20 \\
21 \\
22 \\
23 \\
24 \\
25 \\
26 \mathrm{a} \\
26 \mathrm{~b} \\
27 \\
29 \\
30 \\
32 \\
33 \\
34 \\
35 \\
36 \\
37 \\
39 \mathrm{a}\end{array}$ & $\begin{array}{c}\text { per cent } \\
51 \\
49 \\
42 \\
37 \\
42 \\
46 \\
43 \\
44 \\
53 \\
45 \\
40 \\
50 \\
47 \\
40 \\
47 \\
51 \\
48 \\
49 \\
54 \\
69\end{array}$ & $\begin{array}{c}m l . \\
4820 \\
5030 \\
5660 \\
3580 \\
4960 \\
5180 \\
5660 \\
5040 \\
4880 . \\
4880 \\
6520 \\
6300 \\
4600 \\
5120 \\
5660 \\
5520 \\
6020 \\
6160 \\
5180 \\
5180\end{array}$ & $\begin{array}{c}m l . \\
5960 \\
5980 \\
6860 \\
3830 \\
5000 \\
5460 \\
5910 \\
4320 \\
5640 \\
5160 \\
7230 \\
4950 \\
4250 \\
2260 \\
3120 \\
4900 \\
3610 \\
4450 \\
3410 \\
3060\end{array}$ & $\begin{array}{l}m l . \\
1175 \\
1225 \\
1380 \\
880 \\
1210 \\
1265 \\
1385 \\
1230 \\
1195 \\
1195 \\
1595 \\
1230 \\
1120 \\
1250 \\
1385 \\
1350 \\
1470 \\
1510 \\
1270 \\
1270\end{array}$ & $\begin{array}{c}m l . \\
3510 \\
3840 \\
3470 \\
2280 \\
3160 \\
4010 \\
2710 \\
2170 \\
3620 \\
3320 \\
2870 \\
2660 \\
2670 \\
1200 \\
1860 \\
2260 \\
1620 \\
2010 \\
2200 \\
1240\end{array}$ & 24.5 & $\begin{array}{l}\text { per cent } \\
59 \\
64.5 \\
50.5 \\
59.5 \\
63.5 \\
73.5 \\
46 \\
50 \\
64 \\
64.5 \\
40 \\
53.5 \\
63 \\
53 \\
60 \\
46.5 \\
45 \\
45 \\
64.5 \\
39\end{array}$ & $\begin{array}{l}m m . ~ H g \\
37.5 \\
34 \\
16 \\
18.5 \\
45 \\
41 \\
26 \\
43.5 \\
35 \\
33.5 \\
29.5 \\
27.5 \\
33.5 \\
38 \\
52 \\
50 \\
54 \\
40 \\
21 \\
68\end{array}$ \\
\hline
\end{tabular}




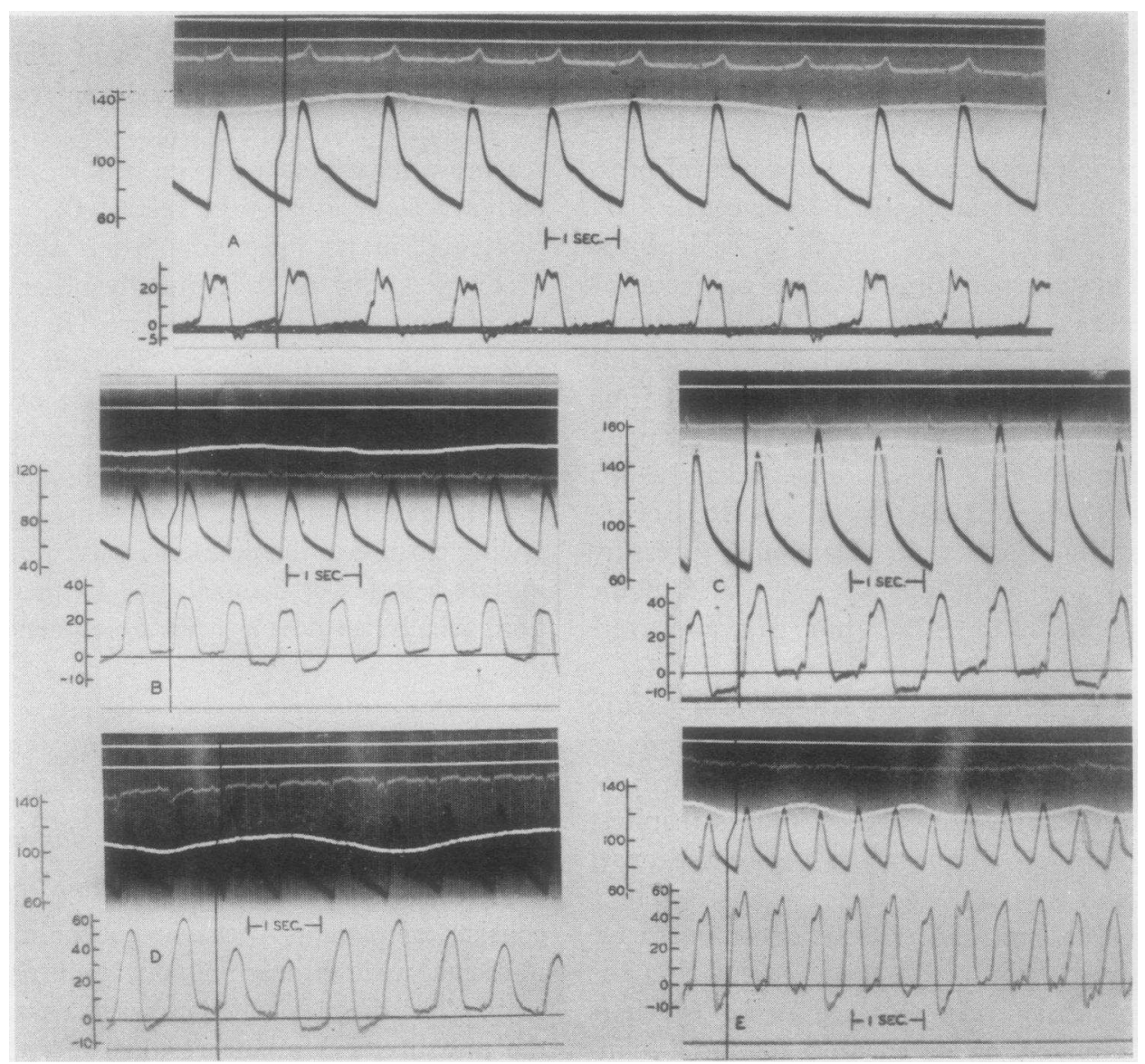

Fig. 3. Ventricular Pressure Records in Chronic Pulmonary Disease

These were recorded in patients No. 27, 31, 23, 25, and 33, respectively, and show gradations from normal values in $A$ to marked systolic elevation, averaging $57.5 \mathrm{~mm}$. $\mathrm{Hg}$, in $E$. Average diastolic pressures are all normal. Note pronounced respiratory variation in all but $A$, reflecting marked pleural pressure changes which occur during the respiratory cycle in chronic pulmonary emphysema (11).

residual air to total lung volume (9), and on the chest $\mathrm{x}$-ray. The diagnosis of pulmonary fibrosis was made on the basis of reduced total lung volume and the $x$-ray picture. Table II presents the data from the lung volume studies, and compares the observed results with the normal values predicted on the basis of age, sex, and body size (10). The hematocrit indicates the degree of secondary polycythemia. At the time of these studies, none of the 19 patients of this group presented clinical evidence of right ventricular failure or had elevation of auricular and diastolic ventricular pressures. In five cases (Nos. 20, 21, 24, 27, and 29) the pressure measurements were either wholly normal or deviated insignificantly from the normal range. All others showed definite elevation of ventricular systolic and pulse pressures, the systolic range being from 34.5 to $57.5 \mathrm{~mm}$. $\mathrm{Hg}$ and the pulse pressure ranging from 30.5 to $54 \mathrm{~mm}$. $\mathrm{Hg}$. The variations observed in this group are illustrated in Figure 3.

2. Post-pneumonectomy. The first patient, a young female (No. 40, Figure 4A), was studied 6 weeks after the right lung had been removed because of a large air cyst. Measurements of the remaining lung indicated some distention associated with moderate displacement of the mediastinum; otherwise lung function was normal. Ventricular systolic pressure was normal and the pulse pressure was only $2 \mathrm{~mm}$. $\mathrm{Hg}$ above the upper limit 

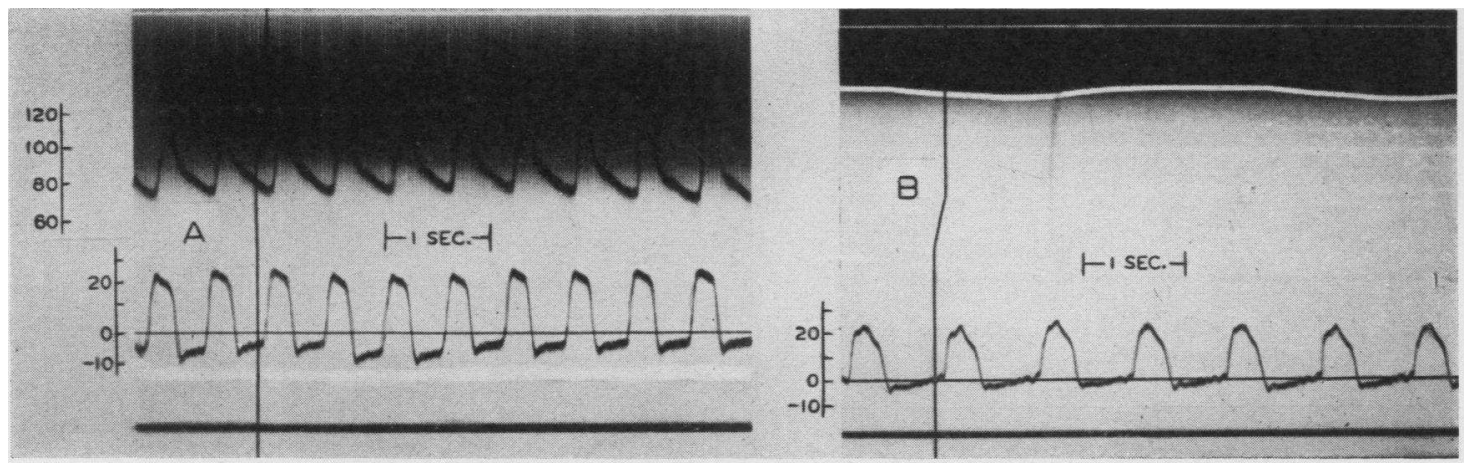

Fig. 4. A. Ventricular Tracing from Patient No. 40, Pneumonectomy

Low diastolic pressure could be due to abnormally low intrathoracic pressure consistent with observed mediastinal displacement, or due to fact that heart was farther than usual below angle of Louis, or possibly to both.

B. Ventricular Pressures from Patient No. 41, Pneumonectomy

Essentially normal record. See text for details.

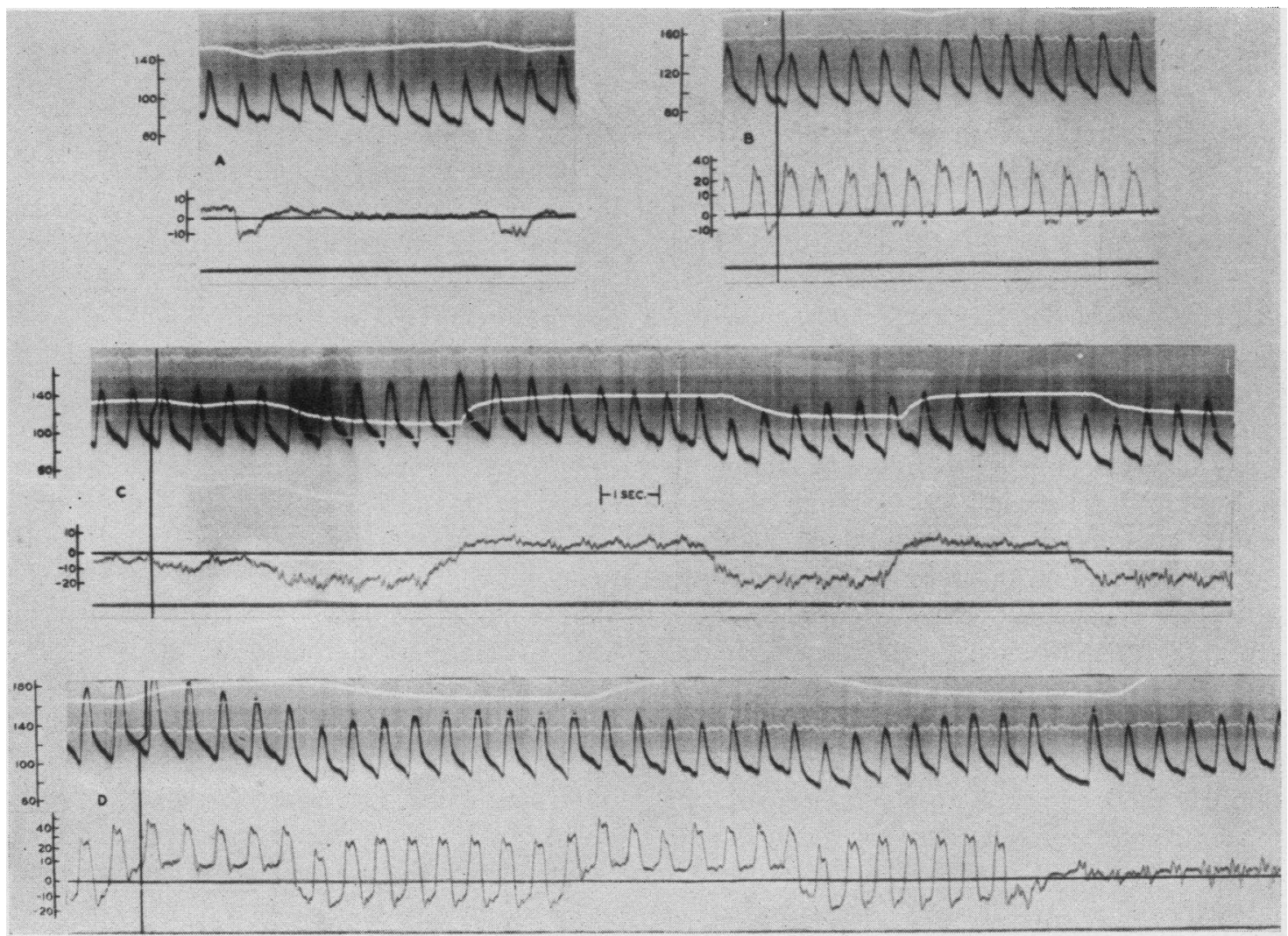

Fig. 5. Patient No. 44, Kyphoscoliosis, with Emphysema and Fibrosis

$A$ and $B$ were recorded during quiet breathing; $C$ and $D$, during deep respiration. Ventricular pulse pressure increase during inspiration in $D$ is distorted by non-linearity of calibration scale. In deep inspiration, near end of $D$, descent of heart caused catheter to slip back into auricle; nodal premature systole was elicited. Descriptive details in text. 
of normal. The second patient, an elderly male (No. 41, Figure 4B), was studied 3 years after the left lung had been removed because of bronchial carcinoma. The function of the remaining lung was normal, and no displacement of the mediastinum was seen on $\mathrm{x}$-ray films. The right ventricular pressures were also normal.

3. Fibrothorax. One of the 2 patients, No. 42, had a complete left fibrothorax following re-expansion of an old pneumothorax. Apical tuberculosis with cavitation, and emphysema, were present on the right; there was marked displacement of the mediastinum to the left. Average ventricular systolic and pulse pressures were normal. The tracings displayed sharp and marked variations in level with normal respiration. The ventricular tracings from the second patient, No. 43, were completely normal.

4. Kyphoscoliosis. The patient studied, No. 44, had emphysema and fibrosis in addition to a marked chest deformity. The average values for the ventricular systolic and pulse pressures during natural respiration were moderately above normal, being 36 and $35 \mathrm{~mm}$. $\mathrm{Hg}$, respectively. Although the auricular mean pressure was normal, the curve (Figure 5A) showed a sharp and brief fall at the beginning of inspiration, probably reflecting the pleural pressure pattern of severe emphysema (11). This phenomenon was likewise seen in the ventricular record (Figure 5B). During deep and prolonged respiration (Figure $5 \mathrm{C}$ ), the auricular pressure varied, as a result of the variation in intrathoracic pressure, from about $18 \mathrm{~mm}$. $\mathrm{Hg}$ during inspiration to about $+8 \mathrm{~mm}$. $\mathrm{Hg}$ during expiration, a range of about $26 \mathrm{~mm}$. $\mathrm{Hg}$. In the ventricular tracing (Figure 5D) made under similar circumstances, the same extreme range is seen in the diastolic pressure level, and for the same reason. It will be noted, however, that the ventricular pulse pressure increased about $10 \mathrm{~mm} . \mathrm{Hg}$ during inspiration, strongly suggesting a greater right ventricular stroke volume during this phase of respiration (12).

5. Pneumothorax. Of the 5 patients in this group, 4 (No. 45 to 48 ) had a therapeutic pneumothorax induced 5 to 23 days prior to the study. In these cases, the right heart pressures, recorded immediately before a refill, were entirely within the normal range. The tracing from patient No. 45 has been shown in Figure 1C. The fifth pa- tient (No. 49) had developed a spontaneous pneumothorax 2 days previous to study and had been maintained on 100 per cent oxygen by mask without intervening aspiration. Here, too, the pressures were normal.

6. Mitral valvulitis with stenosis and insuffciency. Patient No. 50 was a typical case of rheumatic heart disease with clinical evidence indicating involvement of the mitral valve alone. On auscultation, a loud rumble throughout diastole with a marked presystolic crescendo was heard. There were physical and $\mathrm{x}$-ray signs of slight pulmonary congestion and edema, and fluoroscopy revealed enlargement of the left auricle and right ventricle. No signs of right heart failure were present. Peripheral venous pressure was normal. Ventricular systolic and pulse pressures, 43.5 and $41 \mathrm{~mm} . \mathrm{Hg}$ respectively, were almost twice the normal value.

\section{Comment}

It is interesting to find how little evidence of right ventricular strain there may be in some cases of marked pulmonary emphysema or fibrosis. At least 2 of the patients with severe emphysema had normal right ventricular pressures (Table II). In the pneumonectomy cases, the preservation of normal pressure-flow relations could be achieved either by an increase in the number of small blood vessels perfused in the remaining lung, or by a small increase in their diameters. In case the right heart output is diminished, even a lesser increase in the number or in the caliber of the vessels would be required. In the first of the 2 patients (No. 40) the cardiac index of $3.48 \mathrm{~L}$. per minute per sq. $\mathrm{m}$. of body surface was within the normal range; but in the other (No. 41) the cardiac index was 2.28 , which is 73 per cent of the average normal value (3). With regard to fibrothorax and kyphoscoliosis, where variable degrees of mediastinal distortion may be added to variable degrees of reduction in the vascular bed, it is again noteworthy that these conditions are compatible with little or no elevation of right ventricular pressure.

The finding of a high ventricular systolic pressure in the presence of severe mitral stenosis is consistent with the classical conception of the effects of this lesion on the pulmonary circulation and the right ventricle. 
Because the right heart and pulmonary artery have hitherto been inaccessible to direct study in man, the concept of cor pulmonale, i.e. heart disease due to pulmonary disease has been generally less familiar and less understood than the analogous concept of hypertensive heart disease. The mechanical basis, of course, is pulmonary arterial hypertension. The present method makes it possible to detect such hypertension and to express somewhat quantitatively the degree of chronic right ventricular strain, at a time when the peripheral venous and right auricular pressures are normal, and when radiologic and electrocardiographic data may be equivocal or of no clinical value.

\section{$B$. In the presence of right ventricular failure}

It was seen in the patients having chronic pulmonary disease without evidence of heart failure, that when the right ventricular pressure exceeded normal levels, it did so only during systole. So long as the right ventricle, pumping against increased pulmonary resistance is capable of delivering a normal stroke volume under the condition of a normal filling pressure, the patient being at rest, it is considered to be fully adapted to its task; diastolic pressure, as well as auricular and peripheral venous pressures, are then not elevated above the normal. However, when the right ventricle "fails," 4 pressure pulse contours from the right heart and peripheral venous system reveal characteristic peculiarities. While all of the points to be mentioned may not be prominent in any given case, in their entirety the records present the following features: $(a)$ ventricular systolic hypertension; $(b)$ abnormal elevation of the general level of the ventricular diastolic pressure; $(c)$ marked rise of the ventricular diastolic pressure above the minimum which occurs early in diastole, giving rise to a sharp early diastolic "dip" between the arched down-curve of isometric relaxation and the plateau-like remainder of diastole; $(d)$ elevation of the mean auricular pressure; $(e)$ accentuation of the drop in auricular pressure at the time of descent of the base resulting from ventricular ejection; $(f)$ exaggeration of the fall

4 "Failure" is used in its clinical connotation to indicate increased diastolic filling pressure and venous congestion. A clear physiologic distinction between "competency" and "incompetency," "compensation" and "decompensation" of the right heart would require consideration of many factors outside the province of this paper. of pressure in the auricle at the time of rapid emptying into the ventricle, corresponding closely in time with the early diastolic dip in the ventricle (items $(e)$ and $(f)$ give to the auricular curve the shape of a "W" low, item $(e)$ is absent if tricuspid insufficiency is present); $(g)$ elevation of the peripheral venous pressure; $(h)$ appearance of retrograde transmission into the peripheral venous system of intra-auricular pressure variations, especially of the negative waves; $(i)$ diminution of the normal gradient of pressure between the antecubital veins and the right auricle, often to the point where the two differ by but a few mm. of saline $(13,14)$.

1. Chronic pulmonary disease. Patient No. 37 was beginning to recover from right heart failure at the time of study. He was able to be out of bed, but edema persisted. The ventricular diastolic and auricular pressures were still elevated. The ventricular systolic pressure was only slightly elevated to $35 \mathrm{~mm}$. $\mathrm{Hg}$, and therefore the pulse pressure was normal. Because some doubt exists regarding the validity of the tracings during the systolic intervals, no further interpretation is justified at present. The auricular, as well as the ventricular diastolic records are reliable, however, and are typical of right heart failure.

Patient No. 38 was also studied after partial recovery from right heart failure. Ventricular catheterization was unsuccessful. The right auricular curves showed elevation of the mean pressure, as well as the "W" contour, and the peripheral venous pressure, measured with the saline manometer, was above normal.

Patient No. 39 exhibited clinical evidence of right heart failure as a result of advanced pulmonary fibrosis due to silicosis. Studies were done on three separate admissions, during the first and last of which he was in obvious failure, while at the time of the second cardiac compensation had returned. Pressure tracings from the 3 studies are shown in Figures 6 and 7. In Figure 6A the ventricular systolic pressure at $77 \mathrm{~mm}$. $\mathrm{Hg}$, and the diastolic pressure, which ranges between 7 and $9 \mathrm{~mm}$. $\mathrm{Hg}$, are both abnormally high. Because of the low frequency oscillation due to artefact, the early diastolic dip cannot be accurately identified. In the auricular curve artefact also obscures finer details, but the elevation of the mean pressure to $8 \mathrm{~mm}$. $\mathrm{Hg}$ is characteristic. 


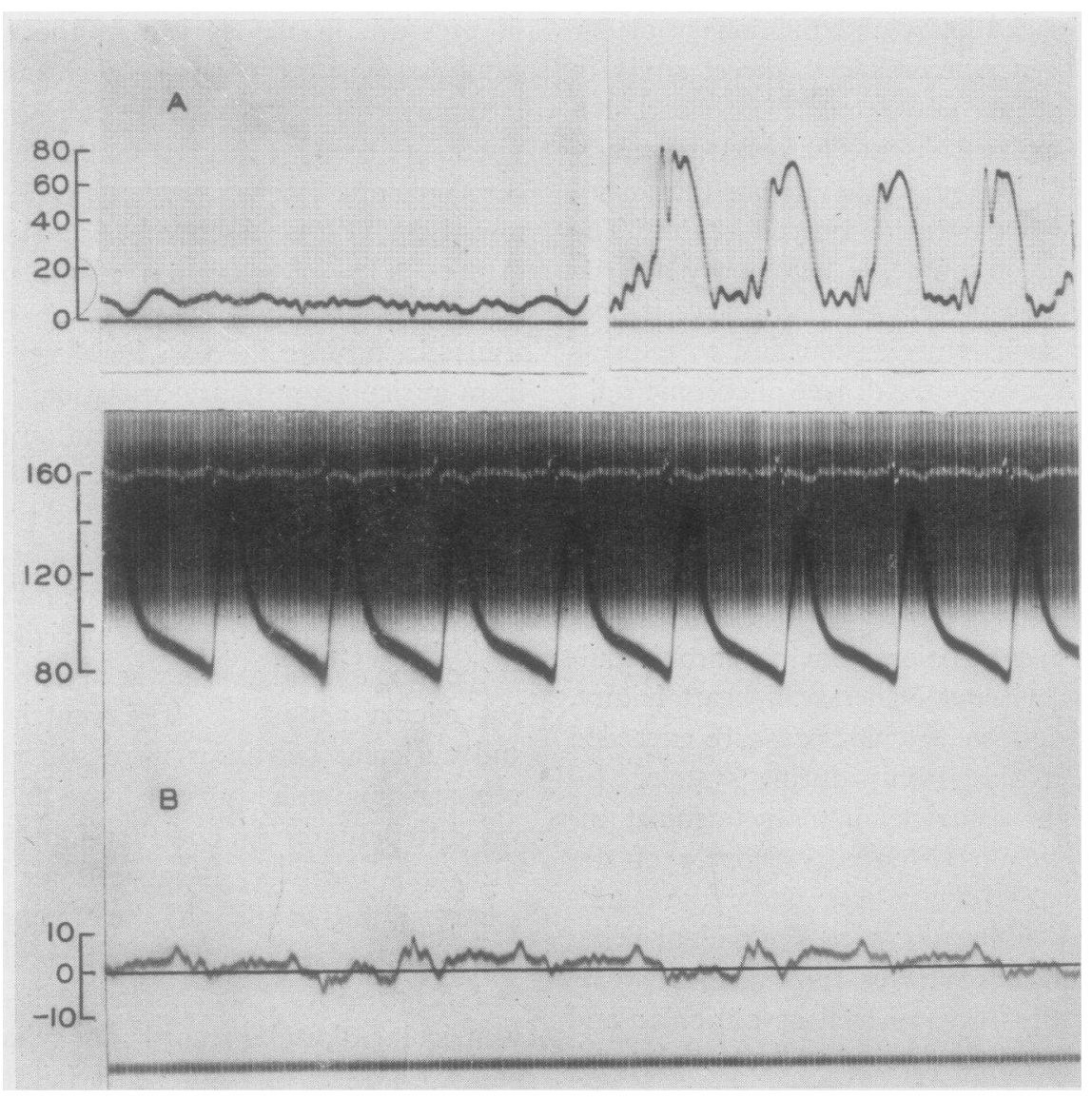

Fig. 6. A. First Study of Patient No. 39, in Right Heart Failure

Left, auricle; right, ventricle.

B. Second Study of Same Patient, Heart Compensated

Auricular pressure has returned to normal. See text for details.

Ventricular catheterization was unsuccessful at the second study, but the auricular tracing has returned to a normal level (Figure 6B).

At the time of the third study tracings were taken from both auricle and ventricle, during quiet and forced respiration. The upper 2 sections of Figure 7, right auricle and ventricle respectively, were made during quiet breathing. High ventricular systolic pressure prevails, and the diastolic and auricular pressures are of the same order as in the first study. The bigeminal rhythm, due to ectopic ventricular beats resulting from digitalis toxicity, lends some striking characteristics to the curves and exemplifies the variety of data which this technique may produce for detailed study. Alternation in the systolic heights and pulse pressures of the ventricular beats is referable to the marked difference in filling time pre- ceding the respective contractions. In the lower 2 sections, recorded during deep respiration, the early diastolic dip following the premature ventricular beats, is especially characteristic during inspiration. However, the premature beats come so early in the diastole of the preceding normal (post-extrasystolic) beat, that the ascending limb of the dip, due to rapid refill from the auricle, merges immediately with the upstroke due to the premature systole, and therefore these dips are not typical. (From a hemodynamic standpoint there are no normal beats in this rhythm; the beats of normal sinus origin follow the longerthan-normal compensatory pause, and therefore are associated with stroke volumes greater than would be expected with a regular and uninterrupted rhythm.)

In the auricle the normal auricular rhythm is 
for the most part uninterrupted, although occasional retrograde stimulation of the auricle by the ectopic ventricular beats, and occasional ectopic auricular contractions, can be made out in the original electrocardiographic tracings. The normal cycle shows auricular systole to be followed by two distinct negative pressure waves forming the "W" contour mentioned above (see

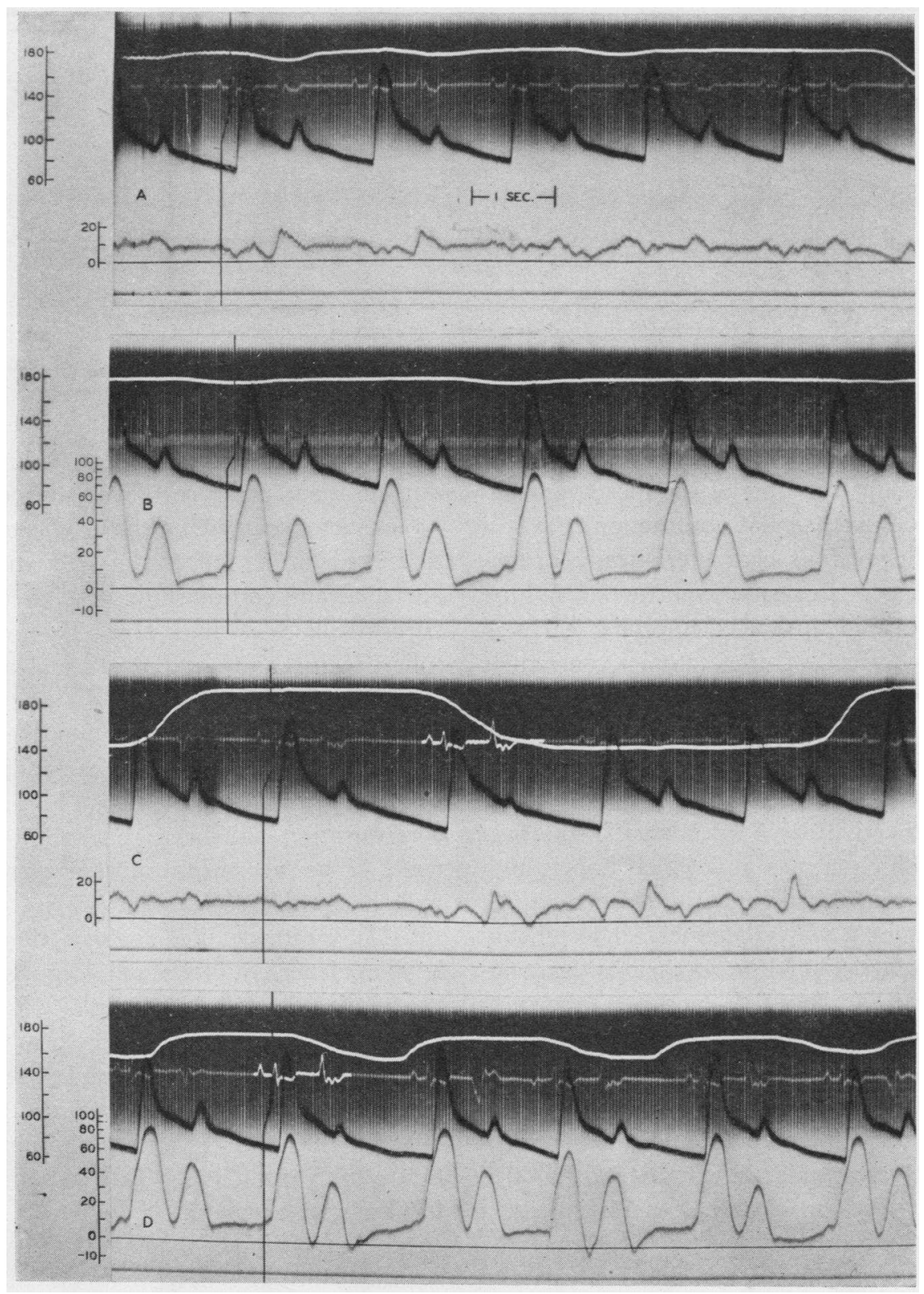

Fig. 7. Third Study of Patient No. 39, Again in Right Heart Failure

$A$, auricle, and $B$, ventricle, during quiet respiration; $C$ and $D$, during deep breathing. Electrocardiogram has been retouched in $C$ and $D$; femoral pulses are obscured by overexposure. Conducted beats have average systolic pressure of $81 \mathrm{~mm} . \mathrm{Hg}$, and pulse pressure of $69 \mathrm{~mm}$. $\mathrm{Hg}$; ectopic beats have average systolic pressure of 40 $\mathrm{mm} . \mathrm{Hg}$, and pulse pressure of $31 \mathrm{~mm}$. $\mathrm{Hg}$. It is obvious from femoral and ventricular curves that the ectopic beats are "abortive" insofar as ventricular output is concerned. Detailed description in text. 


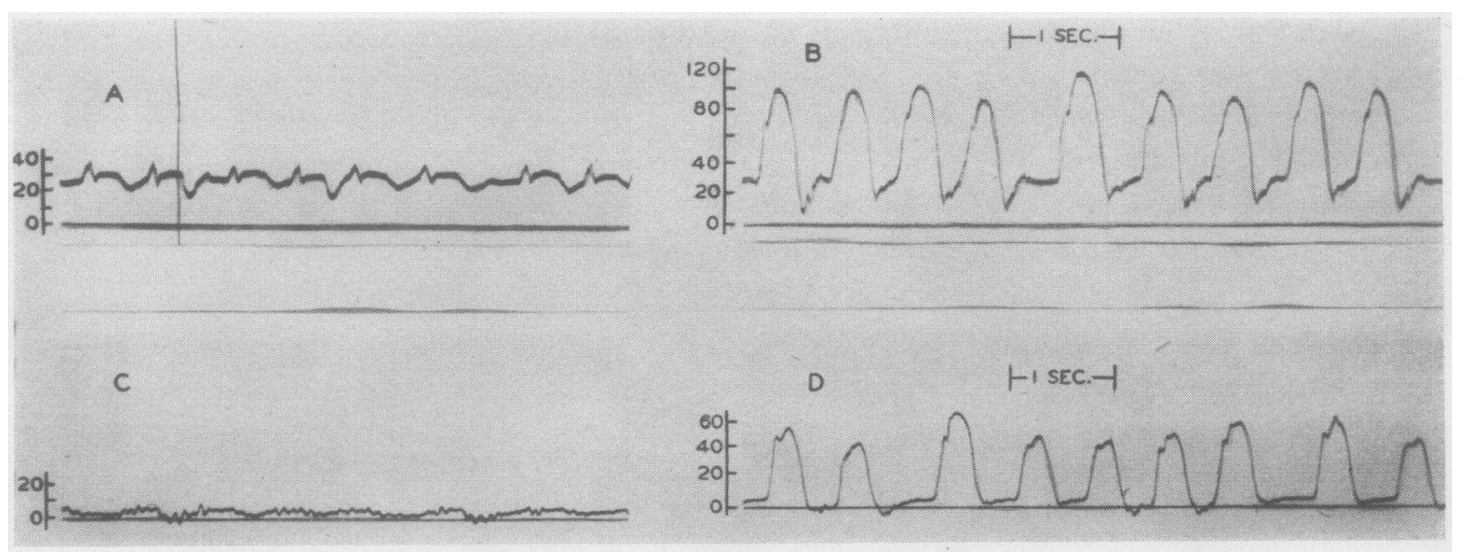

Fig. 8. Patient No. 51, Rheumatic Heart Disease.

$\mathrm{A}$, auricle, and $\mathrm{B}$, ventricle, from first study at time of right and left heart failure. C, auricle, and D, ventricle, from second study, when compensation had been restored. Vertical line in $A$ is crack in film. See text for details.

Figure 7C). The first is due to descent of the base of the heart at the time of the more vigorous post-extrasystolic ventricular contraction; the second is the fall which is characteristically prominent in the presence of right ventricular failure, and is due to rapid auricular emptying early in diastole. The effect of the ectopic ventricular beat on the auricular pressure curve, coming at the time of rapid auricular emptying in the preceding cycle, is striking. The auricular pressure, rising again as the chamber refills from the venous system, is further increased by impact of the premature beat, which occurs at a time of such high velocity flow into the auricle that the effect may be likened to that of a water-hammer. Presumably this weaker ventricular beat occasions less descent of the cardiac base. In addition, the next normal auricular contraction takes place during the course of the impact from the ventricular extrasystole. These factors, auricular refill, extrasystolic impact, incomplete descent of the cardiac base, and auricular systole, all summate to produce the three tall spikes so clearly seen during deep inspiration in the right-hand portion of Figure 7C, during which phase auricular filling from the veins is probably at a maximum.

2. Rheumatic heart disease, with mitral insufficiency and stenosis, aortic insufficiency, tricuspid insufficiency and auricular fibrillation. In Figure 8 are presented the 2 studies of patient No. 51 . The auricular and ventricular curves from the first study (Figure 8A and $\mathrm{B}$ ), recorded when the pa- tient was in left and right heart failure, are typical. An additional feature of the auricular record is its evidence of tricuspid insufficiency, which is discussed in a subsequent section. The mean auricular and end-diastolic $\left(\mathrm{P}_{\mathrm{d}_{2}}\right)$ ventricular pressures are both $29 \mathrm{~mm}$. Hg. The ventricular systolic pressures are at the unusual average height of $103 \mathrm{~mm} . \mathrm{Hg}$, or almost 4 times normal, with considerable individual variation due to the irregular ventricular rate. The early diastolic dip is marked. In the second study (Figures $8 \mathrm{C}$ and D) compensation had been restored following treatment. The mean right auricular pressure is normal, and although the tracing is technically not satisfactory for detailed analysis, there is no longer any evidence of tricuspid regurgitation. The ventricular diastolic pressure is close to zero; the early diastolic dip is barely descernible in some cycles (as in normal curves) and absent from most. The ventricular systolic pressure, though much lower than before, is still at the abnormally high figure of $57 \mathrm{~mm}$. Hg. Two factors may account for such residual systolic hypertension: the persistent congestion of the left auricle and pulmonary vessels behind the more or less fixed barrier of the mitral lesion, and the possible coexistence of secondary pulmonary vascular disease of the type emphasized by Parker and Weiss (15). The pressures now are similar to those found in patient No. 50, already discussed, who had never been in congestive heart failure.

3. Arteriosclerotic heart disease. In Figure 9A 
are a pair of tracings from patient No. 58, recorded through the double-lumen catheter. The left hand portion of the film consists of a peripheral venous tracing (upper) taken simultaneously with an auricular tracing (lower). The auricular channel of the catheter was then quickly attached to the manometer previously connected to the peripheral vein, and the ventricular channel was transferred to the manometer previously connected with the auricle. The right hand portion of the film was then inscribed. Thus it was possible in rapid sequence to use one instrument for comparative recording of vein and auricle, and another for a similar comparison of auricle and ventricle. It is ob-

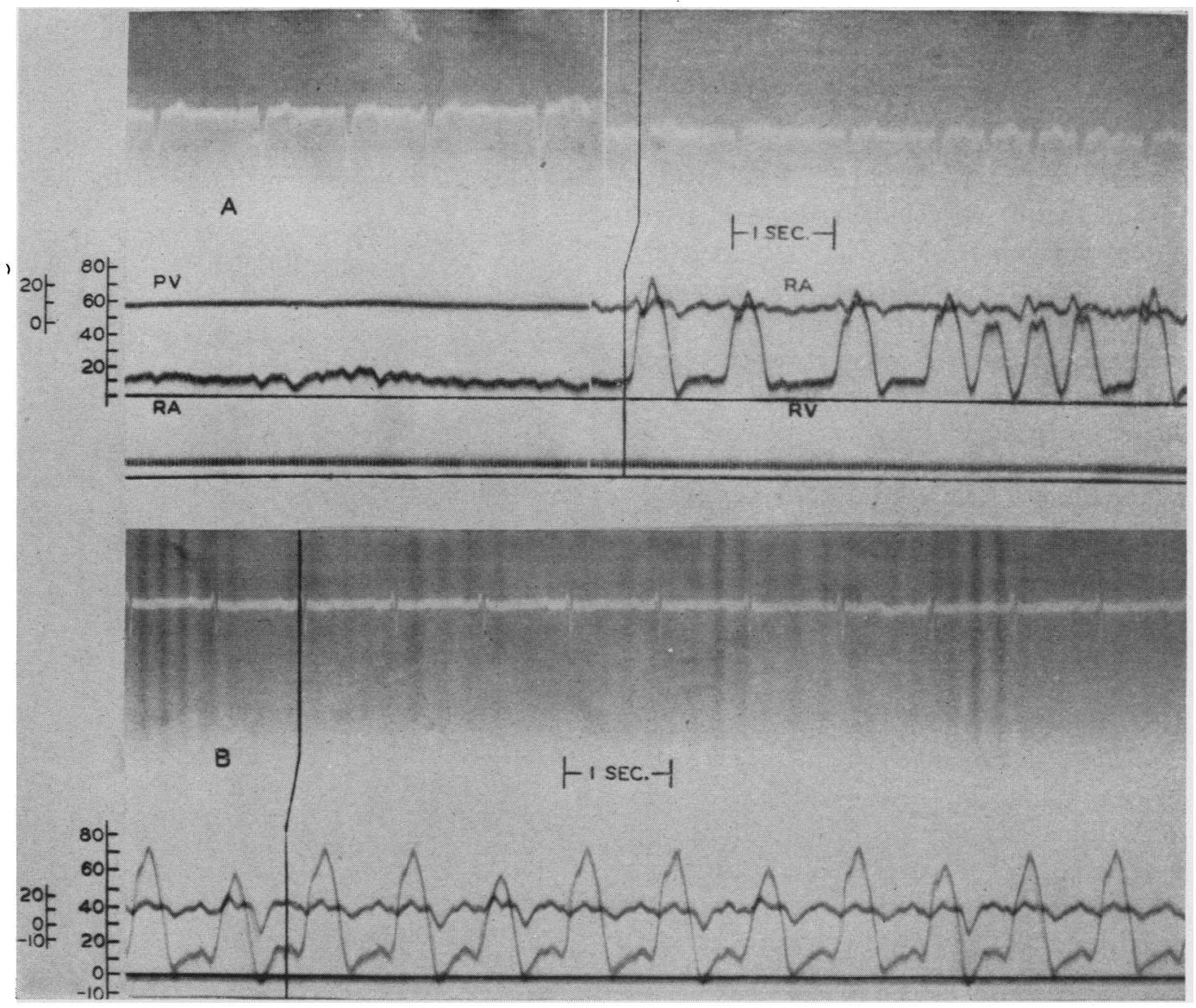

Fig. 9. A. Patient No. 58, Arteriosclerotic Heart Disease, in Failure

Left, simultaneous peripheral venous (PV) and right auricular (RA) pressures; right, right auricular (RA) and right ventricular (RV) pressures, recorded through double lumen catheter (5). The two auricular tracings are not directly comparable because of different sensitivities of manometers. Small scale applies to PV, left, and RA, right; other scale applies to RA, left, and RV, right. Coarse " $\mathrm{f}$ " waves of electrocardiogram appear to correspond to waves in the auricular pressure record. Due to auricular fibrillation, ventricular beats vary in amplitude. Where diastole is short, rising pressure phase of ventricular diastolic curve, i.e., the second portion of the dip, is abbreviated and merges with onset of next contraction. In cycles where dip is prominent, note that it corresponds to rapid emptying phase of auricle. On auricular curve, where ventricular rate is rapid, the same summation of ventricular impact plus refill from veins is seen that was pointed out in case of bigeminal rhythm shown in Figure 7; auricular systole, however, is not present.

\section{B. Syphilitic Heart Disease}

Simultaneous auricular and ventricular curves from patient No. 59, in whom right heart failure is secondary to left ventricular failure. Curves are similar to those of right ventricular failure due to increased pulmonary resistance of other etiologies. 
vious on inspection how close in value are the mean auricular and peripheral venous pressures, which by planimetry were each $10.5 \mathrm{~mm}$. $\mathrm{Hg}$. The correspondence between the auricular and the ventricular diastolic pressures is also apparent. As has been pointed out, the diminution in gradient from peripheral vein to auricle has been a feature of right heart failure, even in the absence of a markedly elevated peripheral venous pressure $(13,14)$. Forward flow in the vein under consideration may still be accomplished, in spite of no mean venous-auricular gradient, as long as the auricular pressure at some time in the cardiac cycle is below that in the vein, as is especially true early in ventricular diastole. The early ventricular diastolic dip and its counterpart in the emptying phase of the auricular record are less prominent than in the preceding case (Figures $8 \mathrm{~A}$ and $B$ ) in which the central venous pressures were much higher. In other respects, however, the auricular and ventricular tracings show the salient features already discussed as exemplifying right heart failure.

4. Syphilitic heart disease, with aortic aneurysm and free aortic regurgitation. Tracings from patient No. 59 are shown in Figure 9B. The initial clinical manifestations were the classical ones of acute left ventricular failure; this was the patient's second episode of decompensation. There was no evidence of pulmonary disease or arteriosclerosis. At the time of study he was in frank right and left heart failure; the cardiac output was only 88 per cent of average normal at a time when the oxygen consumption was 45 per cent greater than the average basal value. The right heart and ventricular pressure pulses, recorded simultaneously through the double-channeled catheter, are characteristic of right heart failure.

5. Heart disease of unknown etiology. Two patients with right ventricular failure of undiagnosed cause were studied. The first, No. 60 , was a 48year-old female, whose history extended over several years and included several hospital admissions. During the first admission she was found to have arterial hypertension associated with left ventricular failure. On a subsequent entry she was suffering from a respiratory infection, which was complicated while in the hospital by a sterile pericardial effusion. At the time of her third admission she was in right- and left-sided failure.
On conventional treatment compensation returned and the first hemodynamic study was then carried out. In addition to the essentially normal right heart pressures shown in Figure 10A, minimal systemic hypertension was present as evidenced by a mean arterial pressure of $112 \mathrm{~mm}$. $\mathrm{Hg}$. The cardiac index was $2.33 \mathrm{~L}$. per minute per sq. m., which is 75 per cent of average normal. On the tracing there is no definite early diastolic dip in the right ventricular curve, diastolic pressure remaining close to zero and varying significantly only with respiration. The right auricular emptying phase is associated with a pressure fall of only

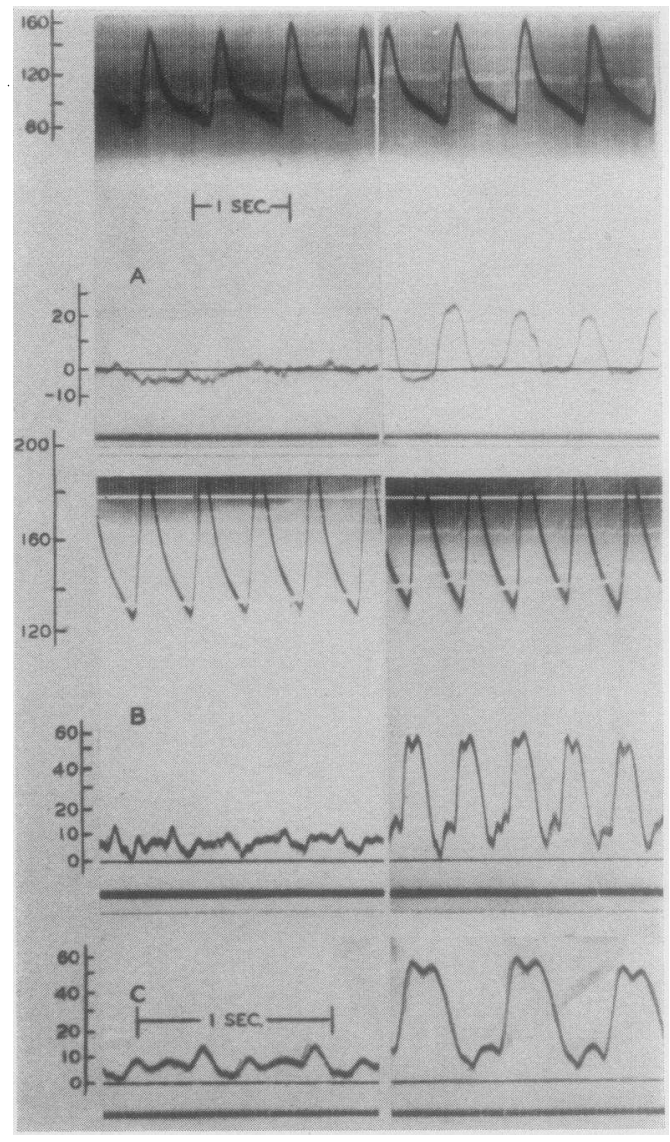

Fig. 10. A. First Study of Patient No. 60, When Previous Heart failure Was no Longer Present

Essentially normal record.

B. Second Study of Same Patient, at Time of Right and Left Heart Failure

Heart rate, 110. Significance of prominent auricular systole in shaping diastolic portion of ventricular curve is discussed in text.

C. High Speed Tracing Showing Details of B 
1 or $2 \mathrm{~mm}$. Hg. The second study of this patient was made on her next admission, at which time she was in right and left heart failure, with a cardiac output 64 per cent of average normal. The expected elevation of right ventricular systolic and diastolic pressures and of right auricular pressures as well as the deep early diastolic dip in the ventricular curve, were present (Figure 10B). Individual details of the cycle are shown more clearly on high camera-speed tracings of Figure 10C. Inspection of the line of decline of ventricular pressure following closure of the pulmonic valve, shows a clear-cut inflection near its base, as a new gradient of pressure marks the beginning (descending phase) of the dip. The ascending limb, and the remainder of diastole apparently corresponds to auricular systoles of unusually great amplitude. The abbreviated ventricular diastole cuts short the period of rapid auricular emptying and its coincident fall in pressure. An unusually vigorous contraction might therefore be expected from the auricle, since its incomplete emptying leaves it under greater stretch at the time its own systole begins. Such an explanation would ascribe to the auricular contraction, in this case, a greater than usual importance for ventricular filling.

The second patient, No. 61, a 37-year-old sailor with a long history of alcoholism, had been admitted several times in complete heart failure. The 2 diagnoses under consideration were active myocarditis of unknown etiology and beri-beri heart disease. During the present admission, in response to conventional therapy, all clinical evidence of heart failure had disappeared by the time the hemodynamic studies were made, but

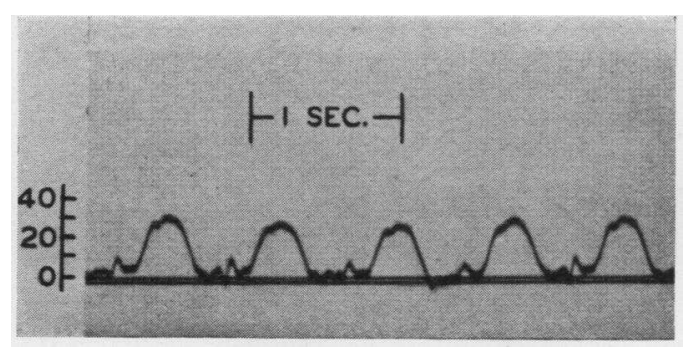

Fig. 11. Patient No. 61, Heart Disease of Unknown Etiology, Not in Failure

Pressure values are normal, but diminished gradient of systolic pressure rise is consistent with hypodynamic heart action. roentgenograms showed persistent and marked cardiac enlargement. The cardiac output was only 74 per cent of average normal. Right heart pressures were normal. Since the mean pulmonary arterial pressure was probably normal, insofar as can be judged from the ventricular curve, and since the cardiac output was less than normal, the pulmonary resistance was presumably increased. It will be seen in Figure 11 that the right ventricular systolic pressure rises more slowly than in normal curves. This decrease in ventricular systolic slope, in the presence of elevated pulmonary resistance, presumably indicates a slower than normal development of mechanical energy by the ventricle. Such hypodynamism has been shown by Wiggers (20) to occur in hearts damaged experimentally by toxins, inadequate coronary blood supply, agents such as chloroform, etc.

\section{Comment}

It would appear from the varied group of cases presented that when increased pulmonary resistance is the cause of clinical right heart failure, pressure pulses from the right heart are generally similar, except when tricuspid insufficiency modifies them, regardless of the etiology or localization of the responsible factor. As might be expected, the pressure pulse records, after compensation is restored, vary from case to case, depending on the degree of residual obstruction to the pulmonary blood flow, and on the stroke volume. Thus in patient No. 51, marked systolic hypertension remained, and the right ventricular curve was similar to that found in patient No. 50 with mitral stenosis who had never been in right heart failure. Both patients with heart failure of uncertain etiology, studied after disappearance of all clinical evidence of heart failure, had normal right heart pressures. However, the cardiac output in both was sufficiently low to suggest that pulmonary resistance was still somewhat above normal. It should be emphasized that in order to estimate resistance, both pressure and flow must be known. Therefore, where a knowledge of cardiac output is lacking, an isolated normal right ventricular pressure record must be interpreted with caution in evaluating the pulmonary resistance, since normal pressures may be found in the presence of obvious and severe heart disease, as evidenced by these 2 patients. 
Properly speaking, in order to measure pulmonary vascular resistance, the mean pressure in the pulmonary artery should be known. Experience with simultaneous recording of pulmonary and right ventricular pressure is very limited. The most satisfactory tracing so far obtained, from patient No. 57, a case of rheumatic valvulitis in cardiac failure, is shown in Figure 12.

\section{Tricuspid insufficiency}

An unusual opportunity has been afforded to observe the auricular pressure pulses in 8 cases of tricuspid regurgitation; in 4 , ventricular curves were also recorded. Seven of these patients, Nos. 51 through 57 , had rheumatic heart disease with multivalvular lesions, and 1, No. 62, had congenital heart disease with a probably large inter-auricular septal defect. All had auricular fibrillation, and all were in heart failure. The tricuspid regurgitation had been clinically suspected in all of the rheumatic cases; the congenital heart case has been added to the group because the tracings were considered diagnostic of the lesion. The heart failure aspects of the records in one patient (No. 51, Figures $8 \mathrm{~A}$ and $\mathrm{B}$ ) have already been cited.

Figure 13 from patient No. 52 is an unusually good example of tricuspid insufficiency in the presence of left and right heart failure. In the upper half of the figure, the right auricular and ventricular pressures were recorded simultaneously without parallax by means of the doublelumen catheter. By this technique, the events of the auricular curve can be easily compared to those of the ventricle. Auricular systole is absent because of fibrillation. At the onset of ventricular systole, the auricular curve displays a brief spike-like rise of pressure, which is probably due to the impact from the contracting ventricle. Concomitant with the downstroke of this spike, there is a slur in the ventricular upstroke, the nature of which is uncertain. It has been ob-

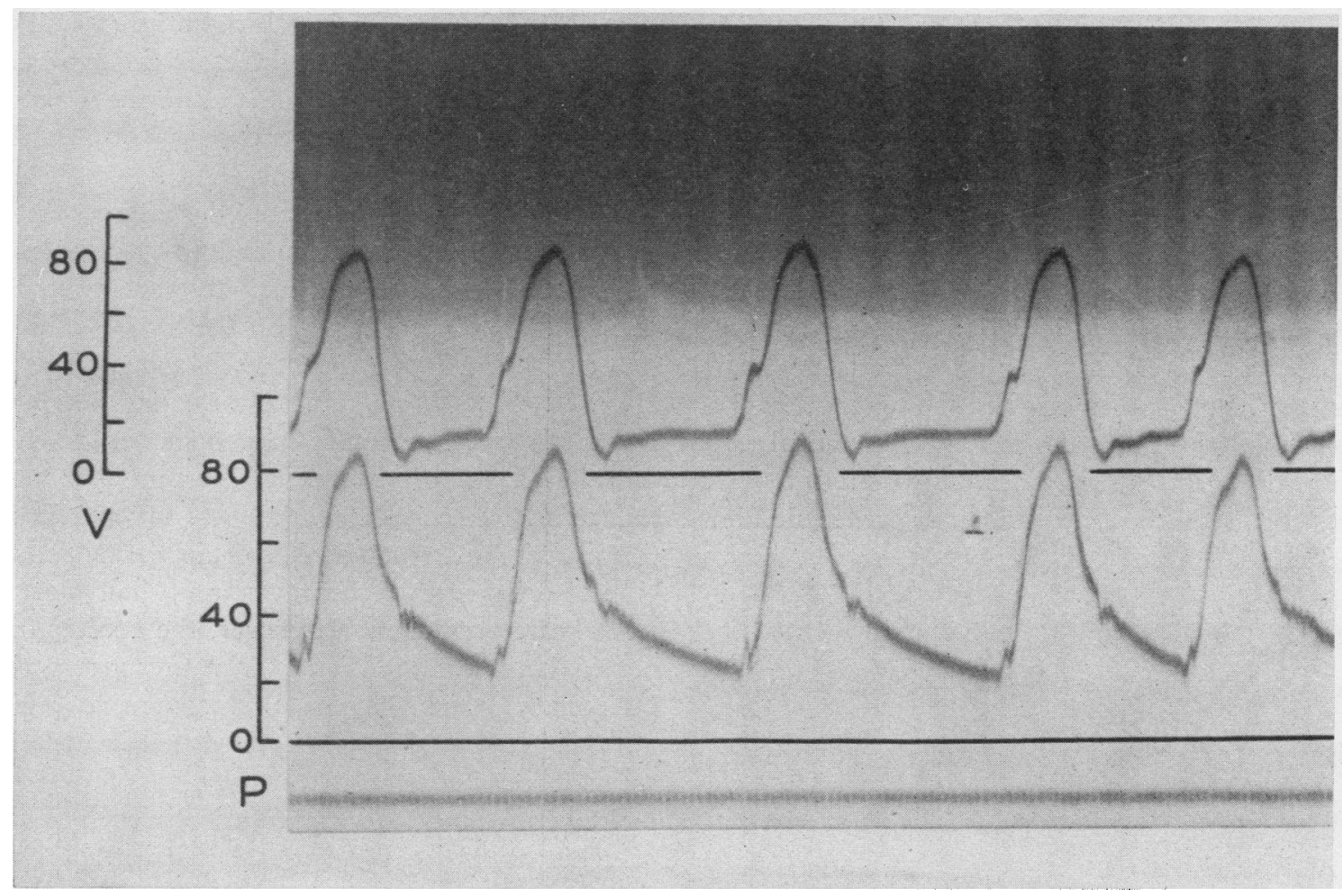

Fig. 12. Right Ventricular (Upper) and Pulmonary Arterial (Lower) Pressures in a Case of Left and Right Heart Failure (Patient No. 57)

Note $(a)$ elevation of systolic as well as ventricular diastolic pressures, $(b)$ identity of contour during most of systole, and $(c)$ identity of maximum systolic values in both tracings. Mean pulmonary arterial pressure is $48 \mathrm{~mm}$. $\mathrm{Hg}$, estimated to be about 3 times normal. 
served in all 4 cases of tricuspid insufficiency in which ventricular catheterization was successful (Figures $8 \mathrm{~B}$ and 12). In the auricle the initial systolic spike is followed by a phase in which the curve is plateau-like or slightly convex upward, representing regurgitation from the ventricle.
Two distinctive features of this plateau are $(a)$ that its pressure level is higher than that prevailing during the presystolic interval (instead of lower, as in normal subjects and in patients with a competent tricuspid valve) and (b) that it is sustained exactly until the end of isometric relaxa-

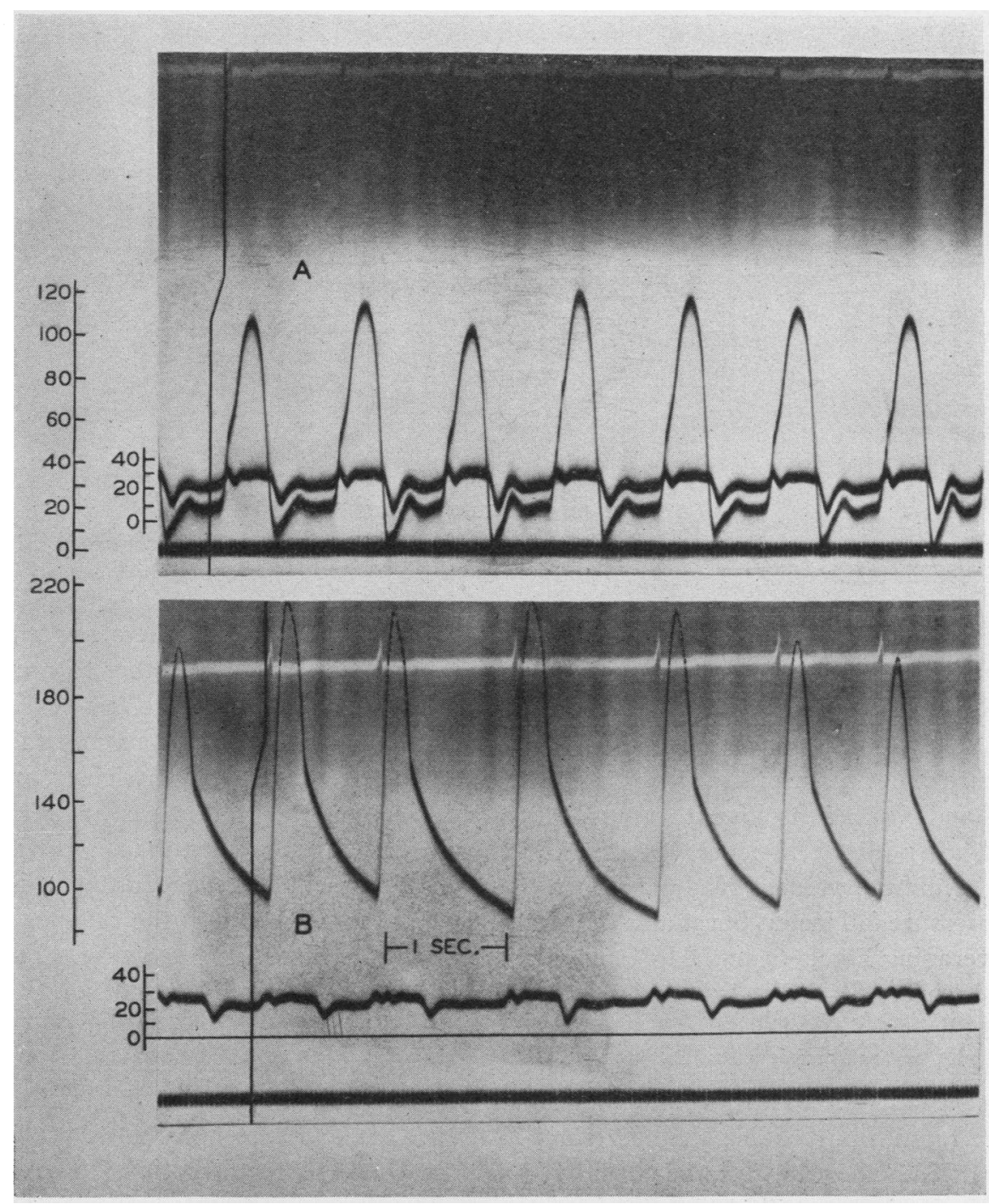

Fig. 13. Patient No. 52, Rheumatic Heart Disease, With Right and Left Heart Failure and Tricuspid Insufficiency

A. Simultaneous auricular and ventricular pressures recorded through double lumen catheter.

B. Femoral arterial and right auricular pressures. Typical features of tricuspid insuffićiency are seen in auricular curves; relationship between auricular emptying phase and early ventricular diastolic dip is especially well shown. Maximum ventricular systolic pressure averages $116.5 \mathrm{~mm}$. $\mathrm{Hg}$, about 4 times normal. The most marked degrees of ventricular hypertension seen were in this patient and in No. 51, both of whom had severe mitral lesions. See text for details. 


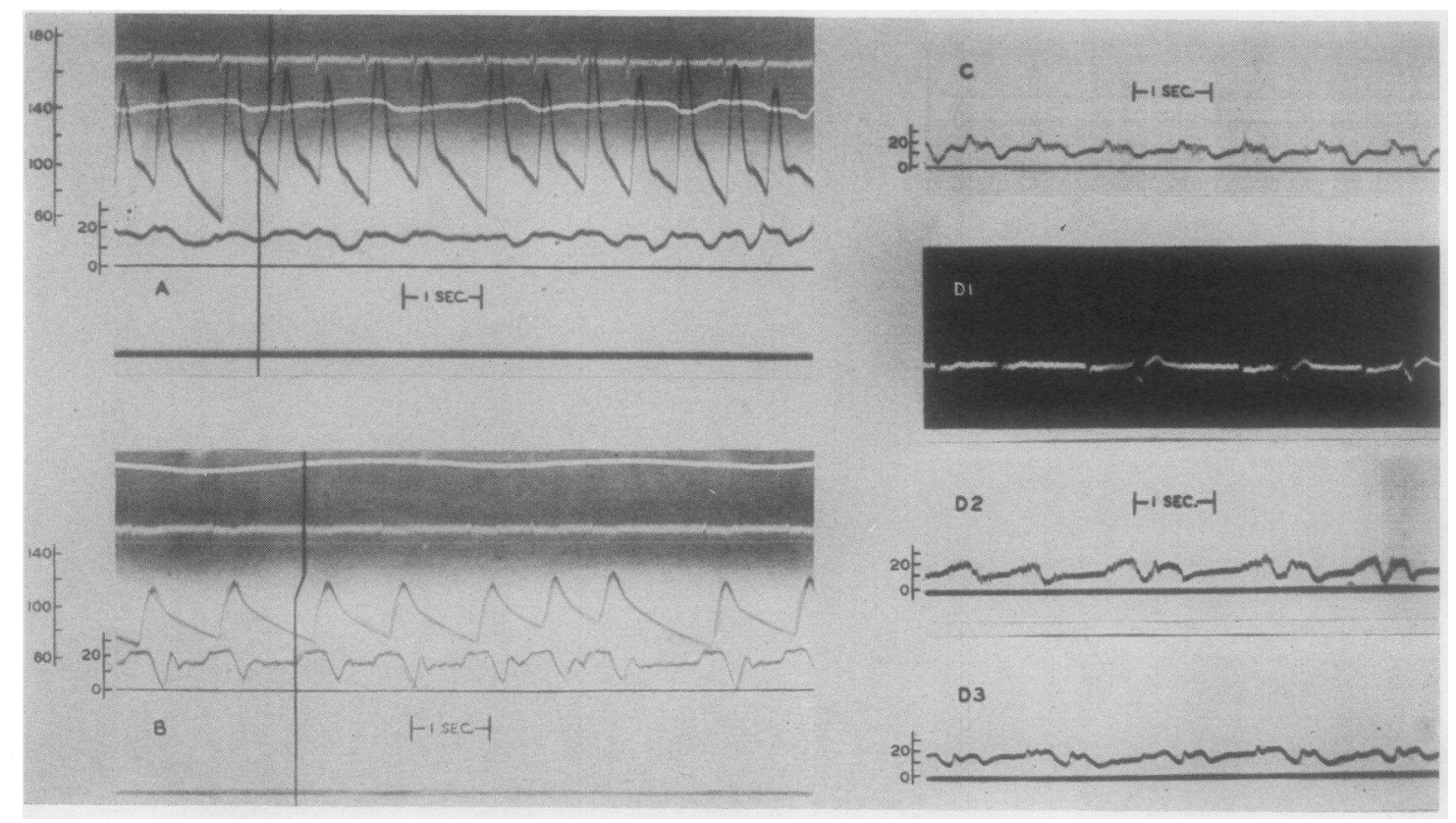

Fig. 14. Right Auricular Records from Patients No. 53, 62, 54, and 55, Respectively, Showing TriCUSPID INSUFFICIENCY

Note similarity of all to auricular pattern of Figure 13. Contrast with normal curves in Figure 1. Further description in text.

tion, at which instant the ventricular pressure falls below the auricular level and the tricuspid valves open. As the pressure in the ventricle continues to fall as a result of the relaxation of its muscle fibers, the auricular pressure also drops, but at a slower rate, and reaches its lowest value 0.05 to 0.06 second after the ventricular pressure has fallen to its minimum value. Not only does the ventricular pressure fall faster, but it also decreases to a level averaging about $6 \mathrm{~mm}$. $\mathrm{Hg}$ lower than that in the auricle. These facts suggest that, in tricuspid insufficiency, at least, it is the relaxation of the ventricle itself which initially creates and momentarily sustains the gradient of pressure that results in the rapid filling of this chamber early in diastole (16). Whether this is to be considered a true aspiration in the sense that the relaxing ventricular wall exerts an outward or enlarging force aspirating blood from the auricle, can probably not be determined from the 2 pressure curves alone. However, Katz and Brams have presented evidence that such is the case in the isolated turtle heart (17) and in the $\operatorname{dog}(18,19)$. The inrush of blood from the auricle under the venous pressure head quickly halts the ventricular pressure fall and then reverses it, whereupon the pres- sures in the two chambers approximately equalize and rise rapidly together to complete the early diastolic dip. During the rest of diastole the pressures are stabilized at the venous level.

The height of the ventricular pressure reached during systole in this case is remarkable, being about 4 times greater than normal.

In Figure 13B, the auricular tracing was recorded after the tip of the catheter had been withdrawn from the right ventricle. The characteristic features of tricuspid insufficiency are even more clearly shown than in Figure 13A. Since both auricular tracings of Figure 13 are practically identical, it is apparent that in this case the presence of the catheter in the tricuspid valve was not the cause of regurgitation. The femoral arterial pressure curve shown in Figure 13B is consistent with the very high peripheral resistance present in this patient (arterial hypertension in spite of subnormal cardiac output).

At post-mortem 3 months later, very marked hypertrophy and dilatation of the right ventricle were found, the walls measuring as much as $\mathbf{1 . 2}$ $\mathrm{cm}$. in thickness in some areas. The mitral valve orifice was extremely narrow. The left ventricle was neither hypertrophied nor dilated. Although 
some thickening of the tricuspid valves at the line of closure was noted, anatomical diagnosis of organic tricuspid insufficiency was not included in the autopsy report.

In Figures 14A, B and C (patients No. 53, 62 and 54), the characteristic features of tricuspid insufficiency are clearly seen, and require no further comment.

In case No. 55 (Figure 14D), where there might well be some doubt as to interpretation of the tracing, an electrocardiogram (D1) taken the same morning revealed long periods of complete heart block during which regularly recurrent ectopic ventricular beats took place, giving rise to bigeminy. The time relationship of the nodal and ectopic beats on the electrocardiogram was found to correspond to the rhythm of the coupled beats on the pressure record. It was thus possible to identify each of these phases with a separate cycle, and to ascertain that each cycle had all the characteristics described for tricuspid insufficiency. Tracing D3 of this figure was taken after the catheter had been withdrawn to the periphery. Except for some damping, it shows a remarkable retrograde transmission of the auricular pressure variations (D2). It should be noted, however, that D3 represents end pressures, since no flow occurred past the portion of the catheter lying in the vein of the arm. The peripheral venous curve (not shown), recorded through a needle in the opposite vein, was much more damped.

Peripheral venous and auricular mean pressures were markedly elevated in the whole group. The existence of a mean pressure gradient which was positive from right auricle to peripheral vein is of considerable interest in cases No. 51, 54, and 55 . The same order of reversed gradient was observed when the respective pressures were measured by saline manometers. It must therefore be inferred that intermittent backward flow in the direction of the distended arm veins takes place, and that a pulsating forward flow of greater magnitude into the right auricle and ventricle occurs early in diastole when the pressure in these chambers falls well below the venous pressure.

\section{Comment}

As is true in right ventricular failure due to elevated pulmonary vascular resistance, the diagnostic pattern of the tracings in tricuspid insuffi- ciency is attributable to a functional abnormality, independent of etiology or lesion. Though the fact of regurgitation seems established, the tracings do not serve to distinguish between insufficiency due to passive dilatation of the valve ring, and that due to organic valve disease. In the rheumatic group either cause or both might have been responsible. One additional point of some diagnostic interest was observed in this study. The attempt to insert the catheter into the ventricle was successful in only half of the cases. In patients No. 53 to 55 , and 62, each time the catheter was pointed in the proper direction to enter the valve, as seen under the fluoroscope, ventricular contraction was observed to cause rejection of the catheter tip which flipped away during systole and returned during diastole to a position pointing toward the valve. This has not been the case in other lesions, and is regarded as evidence of regurgitant flow through the $A-V$ valve at the time of right ventricular systole.

In general, the auricular tracings from cases of tricuspid insufficiency resemble published jugular venous pulse records from patients having this functional defect (20).

Because considerable attention has been given to the description of the early diastolic "dip," it may be well to discuss briefly some points related to its physiological significance: (a) Its occurrence in the auricular and ventricular pressure curves is believed to be of ventricular origin, because the downstroke has a steeper slope and reaches a lower level of pressure in the ventricle than in the auricle. There can be little doubt as to the correctness of this view in the cases of tricuspid insufficiency (Figures 8 and 13), and probably also in the cases of right heart failure without tricuspid insufficiency (Figure 9B). Extension of the same reasoning to the cases with a normal central venous pressure is questionable, since in these cases the ventricular dip may be due, at least in part, to catheter motion. It may be mentioned, however, that the corresponding pressure fall in the auricle (Figure 1A) is accepted in animal tracings as a true pressure record and is attributed to opening of the $\mathrm{A}-\mathrm{V}$ valves and flow of blood into the ventricle (7). The greater amplitude of the dip during inspiration, when the intrathoracic pressure is lower and therefore the inflow into the right heart larger, is consistent with the 
above interpretation. (b) When the venous system and right heart are markedly distended, as in congestive failure with tricuspid insufficiency, small changes in volume will be accompanied by large changes of pressure, the situation being probably analagous to that described for veins by Ryder and Ferris (21). Therefore, when the ventricle relaxes and the auricle empties into the ventricle, the pressure in both chambers falls much farther below the general venous level than in normal cases, although the associated volume displacement is less than normal. Hence, a dip of great amplitude occurs (Figures 8, 13, and 14). In cases of congestive heart failure without tricuspid insufficiency, the same mechanism explains the greater amplitude of the systolic dip in the right auricular tracings, associated with descent of the base.

\section{Constrictive pericarditis}

Auricular and ventricular pressure pulse records were taken as part of a more comprehensive study of a young male with the classical clinical picture of constrictive pericarditis. The tracing resembled

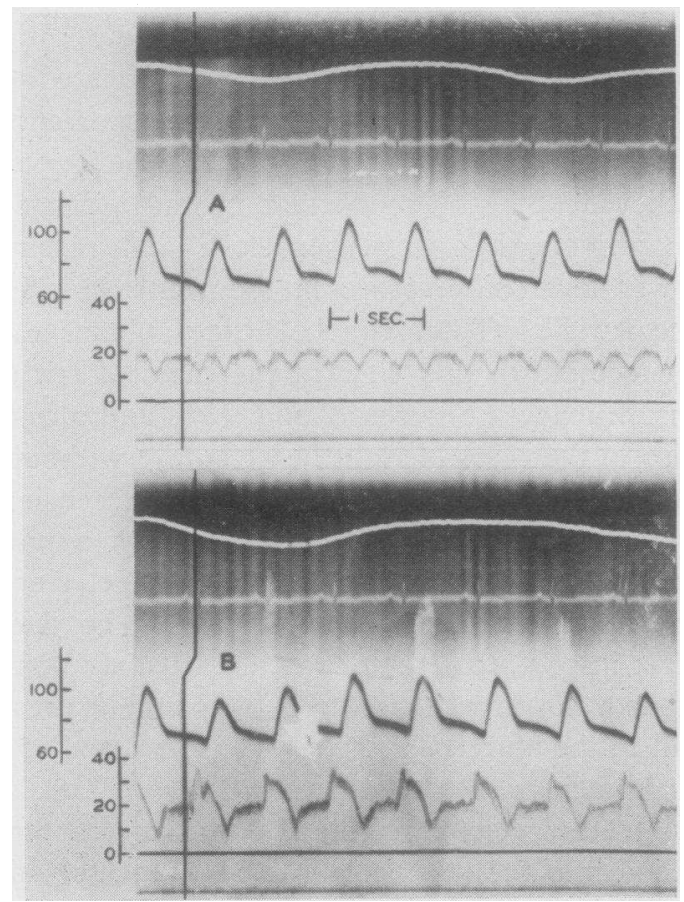

Fig. 15. Patient No. 64, Constrictive Pericarditis See text for details. those described in the section on right ventricular failure without tricuspid insufficiency; however, certain additional features of diagnostic significance were present, which in conjunction with the electrocardiogram and other circulatory measurements form the basis of a forthcoming report. The most obvious of these, as seen in Figure 15, are the existence of a virtually normal ventricular systolic pressure, a low ventricular pulse pressure, a marked elevation of the mean auricular and ventricular diastolic pressures, prominence of the early diastolic dip in the auricle and ventricle, and a marked fall in auricular pressure during ventricular ejection, which, with the diastolic dip, give to the tracing a distinct "W" form.

\section{Arterial hypertension}

Pulse tracings from the right ventricle were essentially normal as to contour and pressure values in the small group shown in Table I, none of whom presented any evidence of either left or right heart failure The mean femoral arterial pressures of $114,132,150,114$, and 128 are all above the normal upper limit taken to be about $110 \mathrm{~mm} . \mathrm{Hg}$. The right ventricular systolic pressures of 21 to $30.5 \mathrm{~mm}$. $\mathrm{Hg}$ are within the range of normal. The diastolic pressures and, by implication, the auricular pressures, are also quite normal, as would be expected. The right ventricular pulse pressure of $28.5 \mathrm{~mm} . \mathrm{Hg}$ in patient No. 67 is only $2 \mathrm{~mm}$. above the highest figure found in the normal series. The results of the present limited study suggest, therefore, that increased systemic arteriolar resistance has no counterpart in the pulmonary circulation; however, definitive conclusions in human essential hypertension should await further investigation.

\section{Shock}

Although the methods used in the study of the patients in the present paper have been routinely employed in many cases of shock $(22,23)$, almost all of the intracardiac pressure curves were technically unsatisfactory. Mean pressure values obtained from auricular records seem to be reliable, when compared with simultaneous readings on saline manometers, but the details of the auricular cycle were for the most part badly obscured by oscillations which were probably artefacts. 
Ventricular pressure curves were even less adequate except in 3 instances : $(a)$ in patient No. 70, a case of chronic anemia due to a bleeding peptic ulcer, who developed signs of mild shock at the time of an acute hematemesis, and in whom the ventricular systolic, diastolic, and pulse pressures were all very low; and $(b)$ in 2 patients in whom acute hypotensive states were deliberately but briefly induced by controlled phlebotomy. Figure 16 summarizes one of these studies in patient No. 13, a small male, 53 years of age. A rapid $600 \mathrm{ml}$. phlebotomy was followed, after a brief interval, by infusion of $650 \mathrm{ml}$. of 5 per cent gelatin solu- tion. The dramatic fall in arterial pressure, associated with marked pallor and a decrease of cardiac output to 40 per cent of the control value, was concomitant with a pronounced reduction in right ventricular pressures, as might be expected. On recovery from the acute collapse the pressures in the ventricle and the systemic arteries returned simultaneously toward normal.

\section{Pharmacodynamic studies}

During the study of shock, observations have been made on the circulatory effects of two pressor amines, both on normal control subjects and on pa-

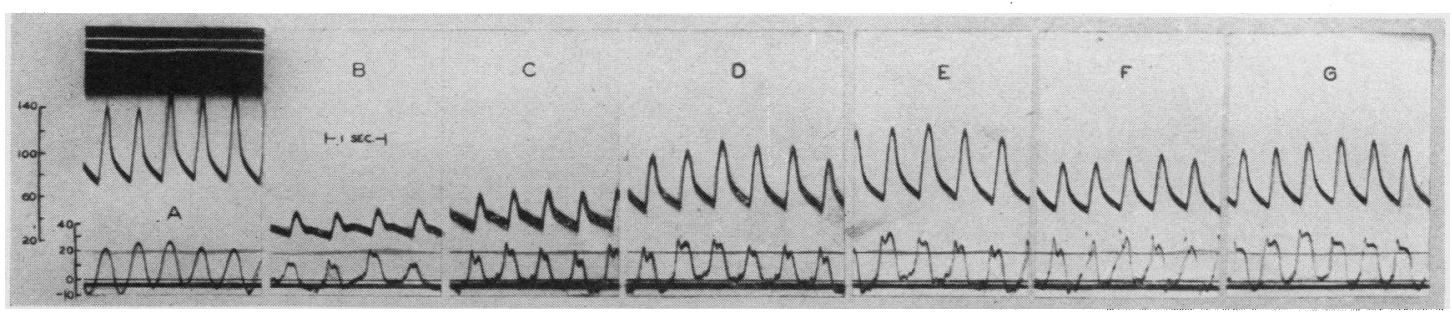

Fig. 16. Induced Hemorrhage in Patient No. 13

$A$, control femoral arterial and right ventricular (damped) pressures.

$B$, same, 5 minutes after $600 \mathrm{ml}$. of blood were removed in 13 minutes; marked pallor, reduced heart rate; cardiac output 40 per cent of control.

$C, 20$ minutes after phlebotomy; $200 \mathrm{ml}$. of 5 per cent gelatin in.

$D, 38$ minutes after phlebotomy; $390 \mathrm{ml}$. of gelatin in.

$E, 57$ minutes after phlebotomy, $600 \mathrm{ml}$. gelatin in.

$F, 86$ minutes after phlebotomy; 25 minutes after end of $650 \mathrm{ml}$. gelatin infusion; cardiac output now 89 per cent of control.

G, 234 minutes after phlebotomy, 173 minutes after infusion; cardiac output now 95 per cent of control.

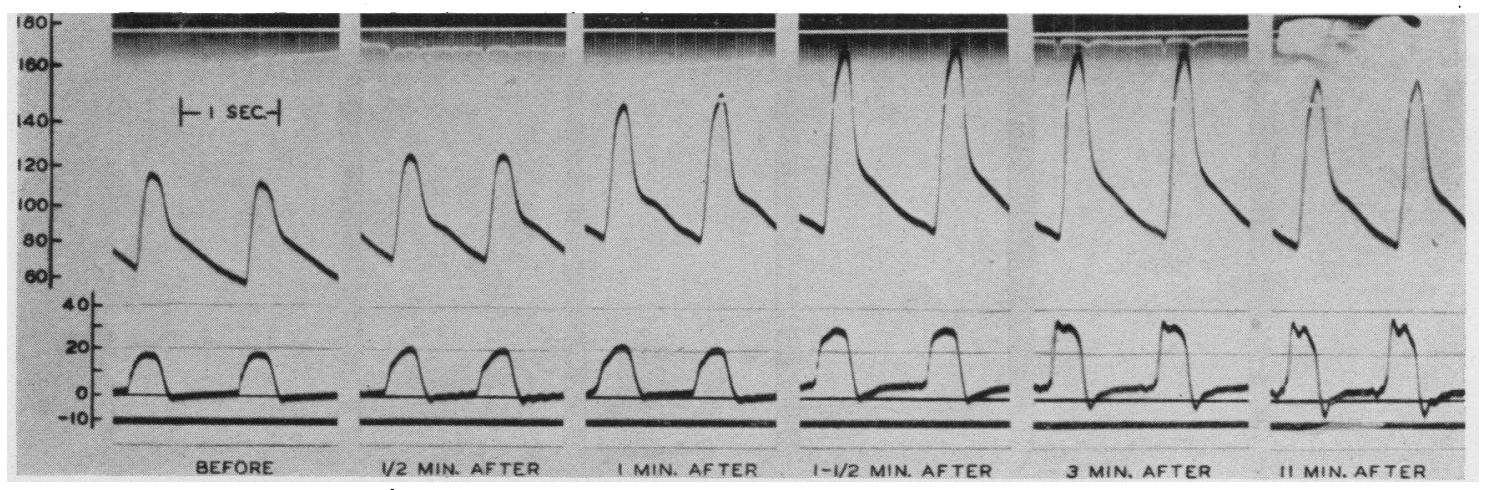

Fig. 17. Effect of Methedrine in Patient No. 3

Each section was taken from same phase of respiratory cycle. Dose was $30 \mathrm{mgm}$., intravenously. Note rapid and concurrent rise in systemic and right ventricular pressures. At $1 \frac{1}{2}$ minutes, the ventricular diastolic pressure and by inference, auricular and central venous pressures, also, have increased appreciably. Thus, pressure is elevated throughout the circ ilatory system. A dip appears at 11/2 minutes, concomitant with increased rate of ventricular relaxation, as judged from steeper slope of pressure curve during isometric relaxation period. Dip is probably exaggerated in last 2 sections by added low frequency vibration. Three minutes after last pressure recording, cardiac output was 117 per cent of control. 
tients suffering from clinical shock. Since changes may occur rapidly after administration and since important changes may be transitory, it is essential to make early and frequent determinations after the control period in order to follow the true sequence of events. Serial tracings made in patient No. 3 following administration of "methedrine" are shown in Figure 17 to illustrate a type of systemic and right heart pressure response that may occur. Such recordings, when taken in conjunction with cardiac output and other measurements, provide a more complete picture of the response to a drug than has been hitherto available in clinical investigation.

\section{Effects of respiration}

An impressive feature of many of the tracings, particularly in the group of patients with disease of the thorax or lungs, has been the rôle played by the variation in intrathoracic pressure in determining intracardiac pressure levels and blood flow. Not only is this factor of importance in hemodynamic considerations, but it is clear that the varying intrathoracic pressure is physiologically a more appropriate base-line from which to measure intracardiac pressures than the atmospheric pressure which it is usually necessary to use (Figure 1C). Figure 5 illustrates a striking influence of deep respiration on the pressures. An example of the effects of cough on the intrapleural, auricular and ventricular pressures is illustrated in Figure 18. A more extended analysis of the respiratory influences on intracardiac pressures will be reported later (12).

\section{SUM MARY}

1. A method is described for recording, singly or simultaneously, the pressures in the right auricle and right ventricle.

2. The method was used in 70 patients without undue discomfort or complication.

3. The form of the tracings and the range of pressure variations are described in 17 normal subjects and 53 patients with the following clinical conditions : chronic pulmonary emphysema, fibrosis, or both, with and without signs of cardiac failure; post-pneumonectomy ; fibrothorax; kyphoscoliosis; pneumothorax; rheumatic heart disease, with and without signs of cardiac failure; arteriosclerotic heart disease and syphilitic heart disease with cardiac failure; heart disease of uncertain etiology; congenital heart disease; constrictive pericarditis; arterial hypertension without cardiac failure; and peripheral circulatory failure.

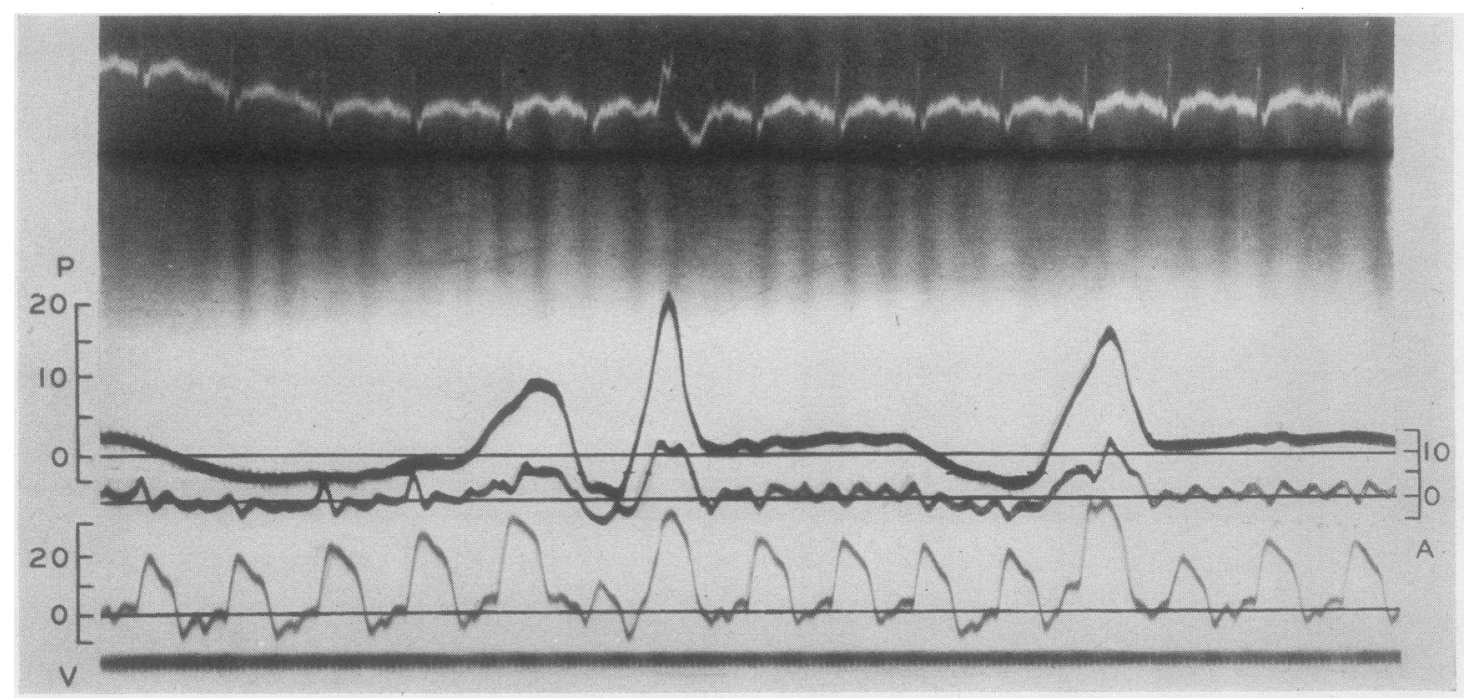

Fig. 18. Illustrating Effect of Sharp Coughs on Intrapleural (Upper), Auricular (Middle). and Ventricular (Lower) Pressures in Patient No. 46

Corresponding calibration scales are labelled $\mathrm{P}, \mathrm{A}$, and $\mathrm{V}$, respectively. Note that changes in right heart pressures are somewhat less than corresponding changes in intrapleural pressure. 
4. The mean right auricular pressure in normal subjects varies from -2 to $+2 \mathrm{~mm}$. $\mathrm{Hg}$, relative to atmospheric pressure. The normal right ventricular systolic pressure ranges between 18 and $30 \mathrm{~mm}$. $\mathrm{Hg}$, and averages $25 \mathrm{~mm}$. $\mathrm{Hg}$. The difference between the systolic pressure and the pressure at the end of diastole, termed the ventricular pulse pressure, ranges from 17 to $26.5 \mathrm{~mm}$. $\mathrm{Hg}$, and averages $22.5 \mathrm{~mm}$. $\mathrm{Hg}$.

5. The existence and approximate magnitude of pulmonary arterial hypertension can be determined in cases in which the right ventricular systolic and pulse pressures are increased.

6. The right ventricular systolic and pulse pressures are elevated in most of the patients with chronic pulmonary disease, but are normal in some cases of advanced pulmonary emphysema. These pressures are markedly elevated in all the cases of primary left heart failure, regardless of etiology.

7. Characteristic patterns of the pressure records in right ventricular failure due to various causes and in tricuspid insufficiency are described and partially interpreted.

The authors gratefully acknowledge their indebtedness to Dr. Domingo M. Gomez for his many helpful suggestions and criticisms; to Dr. Stanley E. Bradley, who helped take the first two ventricular pressure records in man while he was a member of the shock team at Bellevue Hospital; to Dr. William Goldring and Dr. Herbert Chasis, who referred the three patients with essential hypertension; to Dr. Daniel Zahn and other members of the staff of the various divisions of Bellevue Hospital for their kind cooperation in making the patients available for study; and to Dr. Harry Taube who cooperated in the study of methedrine. Measurements of most of the records were made by Miss Sylvia Teich, Miss Vera Collier and Mrs. Vera Andrews; the more recent records were measured by Mrs. Marianne Lester.

\section{BIBLIOGRAPHY}

1. Cournand, A., Lauson, H. D., Bloomfield, R. A., Breed, E. S., and Baldwin, E. de F., Recording of right heart pressures in man. Proc. Soc. Exper. Biol. and Med., 1944, 55, 34.

2. Cournand, A., and Ranges, H. A., Catheterization of the right auricle in man. Proc. Soc. Exper. Biol. and Med., 1941, 46, 462.

3. Cournand, A., Riley, R. L., Breed, E. S., Baldwin, E. de F., and Richards, D. W., Measurement of cardiac output in man using the technique of catheterization of the right auricle or ventricle. J. Clin. Invest., 1945, 24, 106.
4. Cournand, A., Measurement of the cardiac output in man using the right heart catheterization. Fed. Proc., 1945, 4, 207.

5. Cournand, A., Bloomfield, R. A., and Lauson, H. D., Double lumen catheter for intravenous and intracardiac blood sampling and pressure recording. Proc. Soc. Exper. Biol. and Med., 1945, 60, 73.

6. Hamilton, W. F., Brewer, G., and Brotman, I., Pressure pulse contours in the intact animal. I. Analytical description of a high frequency hypodermic manometer. Am. J. Physiol., 1934, 107, 427.

7. Wiggers, C. J., The Pressure Pulses in the Cardiovascular System. Longmans, Green and Company, London, New York, and Toronto, 1928.

8. Bloomfield, R. A., Simultaneous registration of intrathoracic, right intracardiac and systemic pressure in man. Proc. Soc. Exper. Biol. and Med., $1945,60,75$.

9. Hurtado, A., and Boller, C., Studies of total pulmonary capacity and its subdivisions. I. Normal, absolute, and relative values. J. Clin. Invest., 1933, 12, 793.

10. Kaltreider, N. L., Fray, W. W., and Hyde, H. V., Effect of age on total pulmonary capacity and its subdivisions. Am. Rev. Tuberc., 1938, 37, 662.

11. Christie, R. V., The elastic properties of the emphysematous lung and their clinical significance. $\mathrm{J}$. Clin. Invest., 1934, 13, 295.

12. Lauson, H. D., Bloomfield, R. A., and Cournand, A., The influence of the respiration on the circulation in man, with special reference to pressures in the right auricle, right ventricle, femoral artery and peripheral veins. To be published, Am. J. Medicine.

13. Richards, D. W., Jr., Cournand, A., Darling, R. C., and Gillespie, W. H., Pressure in the right auricle of man, in normal subjects and in patients with congestive heart failure. Tr. A. Am. Physicians, 1941, 56, 218.

14. Richards, D. W., Jr., Cournand, A., Darling, R. C., Gillespie, W. H., and Baldwin, E. de F., Pressure of blood in the right auricle in animals and in man: under normal conditions and in right heart failure. Am. J. Physiol., 1942, 136, 115.

15. Parker, F., Jr., and Weiss, S., The nature and significance of the structural changes in the lungs in mitral stenosis. Am. J. Path., 1936, 12, 573.

16. Gomez, D. M., Hémodynamique et Angiocinétique. Etude Rationelle des Lois Régissant les Phénomènes Cardio-vasculaires. Hermann and Co., Paris, 1941.

17. Katz, L. N., The rôle played by the ventricular relaxation process in filling the ventricle. Am. J. Physiol., 1930, 95, 542.

18. Brams, W. A., and Katz, L. N., Studies on the overdistended heart. I. Effects of venesection. Am. J. Physiol., 1931, 98, 556.

19. Katz, L. N., and Brams, W. A., Studies on the overdistended heart. II. The rôle of relaxation in filling the distended and overdistended heart. Am. J. Physiol., 1931, 98, 569. 
20. Wiggers, C. J., Physiology in Health and Disease. 3rd Ed., Lea and Febiger, Philadelphia, 1939.

21. Ryder, H. W., Molle, W. E., and Ferris, E. B., Jr., The influence of the collapsibility of veins on venous pressure, including a new procedure for measuring tissue pressure. J. Clin. Invest., 1944, 23, 333.

22. Cournand, A., Riley, R. L., Bradley, S. E., Breed, E. S., Noble, R. P., Lauson, H. D., Grègersen,
M. I., and Richards, D. W., Studies of the circulation in clinical shock. Surg., 1943, 13, 964.

23. Cournand, A., Noble, R. P., Breed, E. S., Lauson, H. D., Baldwin, E. de F., Pinchot, G. B., and Richards, D. W., Jr., Chemical, clinical, and immunological studies on the products of human plasma fractionation. VIII. Clinical use of concentrated human serum albumin in shock, and comparison with whole blood and with rapid saline infusion. J. Clin. Invest., 1944, 23. 491. 